\title{
Experimental and three-dimensional finite element method studies on pounding responses of bridge structures subjected to spatially varying ground motions
}

\author{
Li-Xiang He ${ }^{a}$, Bipin Shrestha ${ }^{b}$, Hong Hao ${ }^{b}$, Kai-Ming Bi ${ }^{b}$ and Wei-Xin Ren ${ }^{{ }^{*}}$ \\ ${ }^{a}$ School of Civil Engineering, Central South University, Changsha 410075, Hunan Province, China \\ ${ }^{\mathrm{b}}$ Centre for Infrastructural Monitoring and Protection, School of Civil and Mechanical Engineering, \\ Curtin University, Bentley, WA 6102, Australia \\ ${ }^{\mathrm{c}}$ School of Civil Engineering, Hefei University of Technology, Hefei 230009, Anhui Province, China
}

\begin{abstract}
Pounding and unseating damages to bridge superstructures have been commonly observed in many previous major earthquakes. These damages can essentially attribute to the large closing or opening relative displacement between adjacent structures. This paper carries out an experimental study on the pounding responses of adjacent bridge structures considering spatially varying ground motions by using a shaking table array system. Two sets of large scale (1:6) bridge models involving two bridge frames were constructed. The bridge models were subjected to the stochastically simulated ground motions in bi-direction based on the response spectra of Chinese Guideline for Seismic Design of Highway Bridge for three different site conditions, considering three coherency levels. Two types of boundary conditions, i.e., the fixed foundation and rocking foundation, were applied to investigate the influence of the foundation type. In addition, a detailed 3D finite element model was constructed to simulate an experimental case. The non-linear material behavior including strain rate effects of concrete and steel reinforcement is included. The applicability and accuracy of the finite element model in simulating bridge pounding responses subjected to spatially varying ground motions are discussed. Experimental and numerical results demonstrate that non-uniform excitations and foundation rocking can affect the relative displacements and pounding responses significantly.
\end{abstract}

Key words: Shake table test; pounding; unseating; spatially varying ground motion; seismic response; rocking foundation; 3D FEM simulation

\footnotetext{
*Corresponding author: Professor Wei-Xin Ren Tel: 0551-62901432

E-mail address: renwx@ @hfut.edu.cn
} 


\section{Introduction}

Previous earthquakes have shown that bridges always suffer from various types of damages when subjected to strong earthquakes. These damages are identified and classified into three categories by Moehle and Eberhard (2000), namely damages to superstructures, damages to bearings, and damages to substructures. Pounding and unseating are the two most common forms of damage to superstructures ( $\mathrm{Bi}$ and Hao 2013). Seismic induced unseating and pounding damages between adjacent girders or between the girder and abutment in multi-span bridges have been reported in almost every major earthquake, for example, in the 1995 Kobe earthquake (Kawashima and Unjoh 1997), the 1999 Chi-Chi earthquake (Uenishi et al. 1999), and the 2004 Sumatra earthquake (Mondal and Rai 2008). The 2008 Wenchuan earthquake in China revealed that span collapses and pounding of adjacent girders were the typical damage to girder bridges on National Highway 213 (Li et al. 2008). Pounding between adjacent bridge structures and between adjacent buildings were also widely observed in the more recent 2010 Chile earthquake (Kawashima et al. 2011) and the 2011 Christchurch earthquake (Chouw and

\section{Hao 2012).}

Based on reconnaissance reports of many major earthquakes, pounding damage commonly occurred to bridge structures equipped with conventional expansion joints, which were designed to absorb creep, shrinkage and temperature induced deformation, of construction materials. Nevertheless, to ensure a smooth traffic flow, a small expansion joint gap is normally provided, which usually cannot accommodate the relative closing displacement between adjacent components of bridges during strong earthquakes and therefore leads to the pounding damage. Observations from past earthquakes revealed that pounding may lead to local crushing and spalling of concrete at the joint due to impact and friction when adjacent components come into contact with each other. Sometimes pounding can be the primary cause 
of the girder span collapse (Tanabe et al. 1998). In addition to the large relative closing displacement, large relative opening displacement can result in the risk of unseating. As soon as unseating and severe pounding damages took place, the transportation lifeline in the seismic region would be partially or completely cut off, which in turn may result in the irreversible losses to life and economy. It is, therefore, essential for researchers to pay close attention to seismic pounding and unseating to bridge structures. In the present study, seismic induced pounding damage to bridge superstructure is of interest.

Large opening or closing relative displacement can be attributed to the large out-of-phase movements of adjoining bridge segments (either between the girders or between the girder and the abutment). Various reasons may result in these out-of-phase movements. For the long span bridge structures, the different dynamic characteristics of adjacent bridge components and spatially varying ground motions can be the main reasons. Soil-structure interaction (SSI) is another major factor that may induce the out-of-phase vibrations. Although the SSI may not be the immediate cause of seismic pounding, the assumption of a fixed base may lead to an inaccurate prediction of bridge responses (Chouw and Hao 2008b). It should be noted that for the ground motions, three main reasons can result in their variabilities, namely the wave passage effect involving the different arrival times of waves at different locations as a result of the finite wave speed; the loss of coherency owing to reflection, refraction and super-positioning of waves through a heterogeneous soil medium; and the site amplification effect arising from different local site properties (Bi and Hao 2012).

The most straightforward method to avoid seismic pounding and unseating is to provide adequate separation between adjacent segments and sufficient seating length, respectively. Based on this approach, some of the previous studies focused on the relative displacement response in order to yield the necessary separation distance. Penzien et al. (1997) and Hao and 
Shen (2001) analyzed the relative displacement between unequal height buildings under uniform excitation. A spectral difference method was proposed by Jeng and Kasai (1996) to estimate the maximum relative displacement between adjacent structures considering wave passage effect. Hao and Liu (1998) and Hao and Zhang (1999) studied the effect of building properties and non-uniform ground excitations on required separation distance between adjacent buildings to avoid pounding. However, the bridges with conventional expansion joints usually can't provide such a significant separation distance between bridge decks in order to allow a smooth traffic flow as mentioned above.

To overcome the limitation of conventional expansion joints, a modular expansion joint (MEJ) system is developed and used in some newly constructed bridges. MEJ allows a large relative movement at the joint and makes avoidance of pounding between bridge decks possible (Chouw and Hao 2008a). Chouw and Hao (2008a) analyzed the relative displacement between two adjacent bridge frames connected by an MEJ, considering the influence of ground motion spatial variation and SSI. Recently, by conducting stochastic analyses in the frequency domain, Bi et al. revealed that neglecting ground motion spatial variation (2010) and SSI (2011) may result in underestimation of the required separation distance between adjacent bridge decks. Through parametric studies on various two-span simply supported bridges with non-uniform excitations at the supports, Hao (1998) confirmed that dynamic parameters of structures, spatial ground excitations and damping ratios can have significant influence on the required seating length. Ruangrassame and Kawashima (2001) investigated the relative opening displacement spectra by taking pounding effect into account and found that pounding may lead to considerable increasing in the required seating length for preventing the unseating of bridge decks. 
Pounding is a complicated phenomenon due to plastic deformation, local cracking and crushing. To simplify the analysis, many researchers modeled every component of a structure involved in potential impacts as a single-degree-of-freedom (SDOF) system by considering a bridge girder or building floor as a lumped mass (Maison and Kasai 1992; Jankowski et al. 1998; Ruangrassamee and Kawashima 2001; Chau et al. 2003; Anagnostopoulos 2004; Jankowski 2005; Muthukumar and DesRoches 2006; Komodromos et al. 2007; Chouw and Hao 2008a,b; Ye et al. 2009), while some other researchers built finite element (FE) models by adopting beam-column elements (Hao 1998; Kim and Shinozuka 2003; Bi et al. 2010, 2011; Shrestha et al. 2014, 2015). Based on these two types of simplified FE models, the impact between adjacent segments can be simulated by a number of methods, which can be roughly classified into two categories, viz, stereo-mechanic method and impact element method (Khatiwada et al. 2014). The stereo-mechanic method is based on conventional impulse-momentum principle. The loss of energy during impact is described by the coefficient of restitution, which is defined as the ratio of post-impact to pre-impact relative velocity between two impact segments. Some researchers have employed this method to calculate the seismic pounding response due to its clear physical meaning (Malhotra 1998; Mouzakis and Papadrakakis 2004; Cole et al. 2011). But a wider adoption of the stereo-mechanic method is limited since it is difficult to incorporate into FE analysis and it could not predict the pounding force.

Impact element method usually connects adjacent bridge components with an impact element consisting of a spring, a damper and a gap element. The impact element will be activated when the relative closing displacement between adjacent segments exceeds the initial gap size. The spring and damper is used to consider the pounding forces and energy dissipations during pounding. Various linear and non-linear impact element models have been proposed, such as 
the linear spring model (Maison and Kasai 1992; Kim and Shinozuka 2003), Kelvin model (Jankowski et al. 1998; Anagnostopoulos 2004; Komodromos et al. 2007), Hertz model (Davis 1992; Pantelides and Ma 1998; Chau and Wei 2001; Chau et al. 2003), Hertz-damp model (Muthukumar and DesRoches 2006; Ye et al. 2009), nonlinear viscoelastic model (Jankowski 2005, 2006, 2007), and Hunt-Crossley model (Khatiwada et al. 2014) to simulate the pounding phenomenon of adjacent structures. The advantage of this method is that it has a clear physical theory and can be executed easily in FE analysis. However, the stiffness of the impact element cannot be determined by a suitable and uniform method (Khatiwada and Chouw 2014). The impact stiffness has a significant effect on the pounding force (Anagnostopoulos 1988) and the convergence of the calculations. Moreover, a common drawback of all the methods mentioned above is that just point-to-point pounding could be considered and the pounding location has to be pre-specified. As such, only frontal impact of bridge structures subjected to simple longitudinal ground motions can be taken into account by these methods. In the reality, pounding could take place along the entire surface of the adjacent segments (Hao et al. 2013), namely surface-to-surface pounding. Most poundings actually occurred at corners of bridge decks as observed from previous earthquakes (Hao et al. 2013). This results from the eccentric pounding induced by torsional vibration of adjacent bridge girders due to spatially varying ground motions, especially spatial variation of the transverse excitations.

To model realistic pounding phenomenon involving surface-to-surface contact and eccentric pounding between adjacent bridge structures, all these simplified models and methods are incapable, a detailed 3D FE model need to be developed. Zhu et al. (2002) proposed a 3D contact-friction model to study the pounding response in seismic events. This model is suitable to analyze the point-to-surface contact and eccentric pounding between bridge girders 
considering the friction in the tangential direction, and overcomes the limitation of predefining the pounding locations. Guo et al. (2011) developed a modified contact-friction element based on the 3D contact-friction model to represent point-to-surface impact, considering two different contact statuses during the pounding. Bi et al. (2013) developed a 3D FEM to consider surface-to-surface and torsional response induced eccentric poundings between adjacent bridge components by using LS-DYNA. It should be noted that the above mentioned methods cannot consider the plastic deformation and localized damages at the joints during the poundings. To overcome this limitation, Bi and Hao further developed their previous model (Bi et al. 2013) by incorporating the non-linearities of the materials into consideration, and studied the pounding effects between bridge girders (2013) and between bridge girder and shear keys (2015).

It can be seen that though pounding response between adjacent structures have been studied widely, most of the studies were conducted numerically, experimental investigations were relatively rare. The impacts between a concrete pile and a concrete block were experimentally investigated by Van Mier (1991). Jankowski (2010) performed two experimental studies on the interactions between elements made of four building materials. Filiatrault et al. (1995), Papadrakakis et al. (1995), and Chau et al. (2003) conducted the shake table experiments on pounding between adjacent buildings. Zhu et al. (2002) performed two experimental studies to verify the proposed 3D contact-friction pounding model. Guo et al. (2009) carried out a series of shaking table tests on a 1:20 scaled base-isolated bridge model to investigate the effects of pounding on the response of the structures subjected to earthquake ground motions and pounding mitigation by using magneto-rheological (MR) dampers. A 2:5 scale curved bridge model was constructed to be tested on the four shake tables by Wieser et al. (2012) to study the poundings at the abutments with an equivalent nonlinear backfill soil during strong 
earthquakes. It should be noted that all the above studies neglected the spatially varying ground motions. More recently, Li et al. (2012) tested a three-segment 1:125 scaled bridge model using three shake tables to investigate the pounding effect on the bridge behavior under spatially non-uniform ground motions. Though, the study provided valuable information on the effect of spatially non-uniform ground motions on the bridge responses, it may not provide a realistic picture of responses due to the very small scaled bridge model constructed with materials different from that used in the prototype structure, as well as due to the omission of the inelastic responses of bridge structure.

This paper presents an experimental study on the pounding responses of adjacent bridge structures considering spatially varying ground motions by using a shaking table array system in Central South University, China. Two sets of large-scale (1:6) bridge models involving two bridge frames were designed and constructed. Two types of boundary conditions, i.e. the fixed foundation and rocking foundation were tested to investigate the influence of the foundation types. To the best of knowledge of the authors, experimental studies on the pounding responses of adjacent bridge structures to spatially varying ground motions by using such a large scale model has never been reported in the literature. Moreover, a detailed 3D finite element model is constructed to simulate one of the experimental cases in general purpose FE software, LS-DYNA. The non-linear material behavior including the strain rate effects of concrete and steel reinforcement are considered in the numerical simulation and pounding induced damages are simulated.

\section{Experimental details}

\subsection{Prototype structure and model}

The bridge models for the experiment were scaled representation of a prototype bridge consisting of two frames of $50 \mathrm{~m}$ length each. The test models were properly designed and 
constructed according to the scaling law as presented in Table 1. In order to simulate inelastic deformation of the structure, reinforced concrete of the same grade as the prototype bridge was used for the model. The bridge model consisting of two concrete bridge frames with post-tensioned girder (rigid T-shape girder) was constructed as shown in Figure 1. In order to simulate the expansion joint, the two frames were separated by a gap with a size of $8 \mathrm{~mm}$. The length of each scaled bridge frame was $8.33 \mathrm{~m}$ and the total length of the bridge model was $16.67 \mathrm{~m}$. The superstructure of the bridge is a post-tensioned box girder with variable cross section. The bent of the bridge model frame consists of two square piers with the cross section of $0.25 \mathrm{~m} \times 0.25 \mathrm{~m}$ and the height of $1 \mathrm{~m}$. To keep the same fundamental vibration frequency of the scaled model and the prototype structure, additional weights of 15.6 tones (12 concrete blocks with mass of 1.3 tones) were placed on each frame. It should be noted that in some cases, the additional masses would be adjusted to achieve different dynamic properties of the two frames, as will be discussed latter. For safety consideration, the additional masses were fixed on the deck top by mortar and secured by using additional steel bars. Figure 2 presents the overall view of the bridge model with additional mass placed over it.

Table 1 Scale ratios of the model structure

\begin{tabular}{ccc}
\hline Physical quantity & Similitude & Scale factor(N) \\
\hline Length, $\mathrm{L}$ & $\mathrm{N}_{\mathrm{L}}$ & 6 \\
Acceleration, a & $\mathrm{N}_{\mathrm{a}}$ & 1 \\
Stiffness, $\mathrm{E}$ & $\mathrm{N}_{\mathrm{E}}$ & 1 \\
Mass, $\mathrm{M}$ & $\mathrm{N}_{\mathrm{M}=\mathrm{N}_{\mathrm{E}} \mathrm{N}_{\mathrm{L}}^{2} / \mathrm{N}_{\mathrm{a}}}$ & 36 \\
Time, $\mathrm{t}$ & $\mathrm{N}_{\mathrm{t}}=\sqrt{ }_{(} \mathrm{N}_{\mathrm{L}} / \mathrm{N}_{\mathrm{a}}$ & 2.45 \\
Force, $\mathrm{F}$ & $\mathrm{N}_{\mathrm{F}}=\mathrm{N}_{\mathrm{M}} \mathrm{N}_{\mathrm{a}}$ & 36 \\
\hline
\end{tabular}



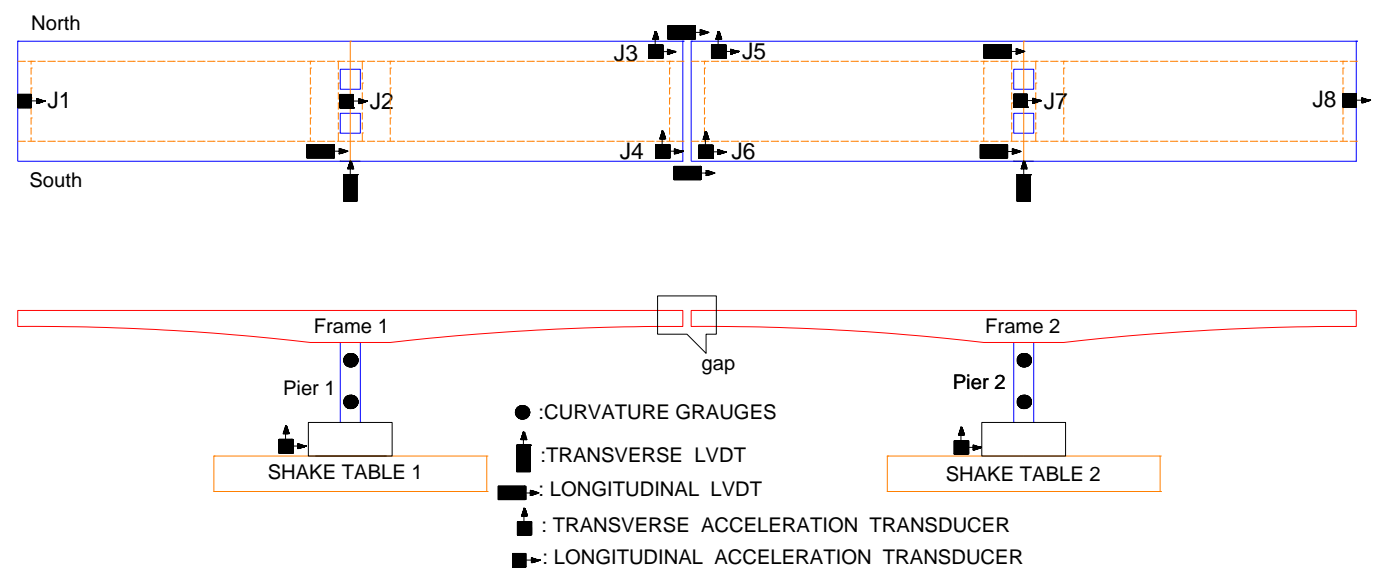

Fig.1 Design of the bridge model and arrangement of sensors

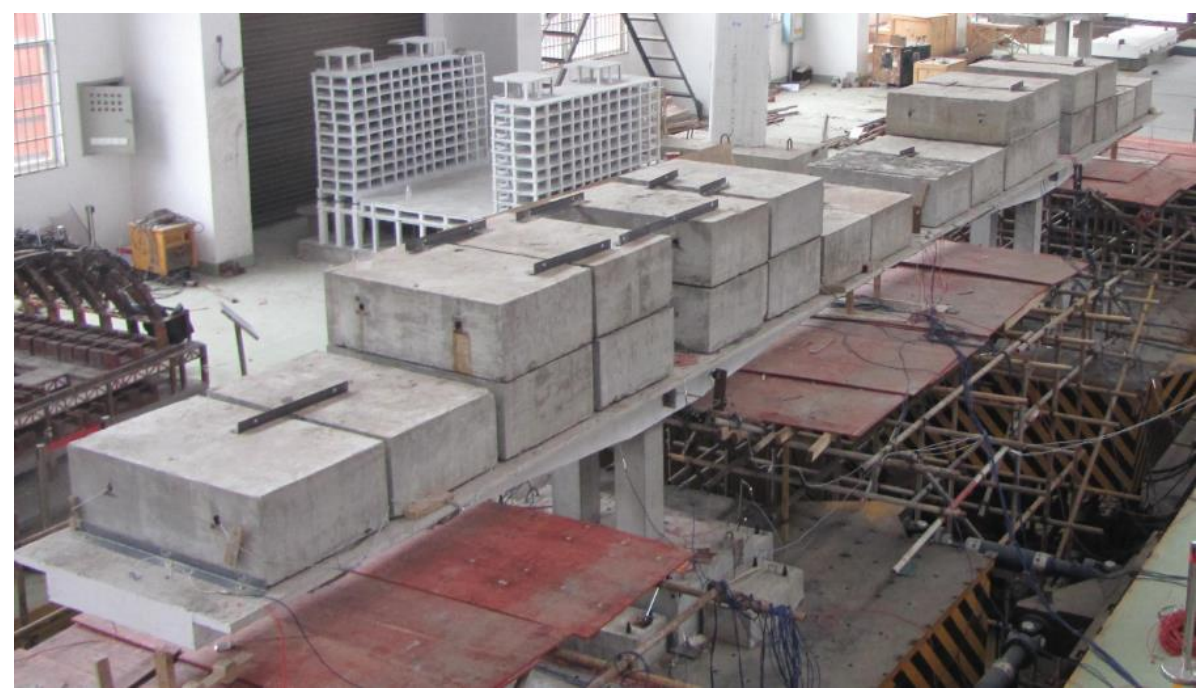

Fig.2 Overall view of the bridge model

\subsection{Boundary conditions}

Two sets of bridge models were prepared in the tests. These two sets were tested for two boundary conditions, i.e. fixed foundation and rocking foundation. For a fixed foundation condition, the bridge model was fixed on the shake table platform by high-strength bolts through the reserved holes on the footing. For the rocking foundation, the foundation structure was specially designed: the uplifting of the footing was allowed by not restricting the vertical movement of footing; Between the footing and shake table platform, a piece of $10 \mathrm{~mm}$ thick 
rubber was inserted to consider the stiffness and compressibility of supporting soils; To restrict the motion in the horizontal directions, concrete blocks were anchored around the footing with $40 \mathrm{~mm}$ thick rubber blocks filling the gap between them. Figure 3 shows the details of the rocking foundation.

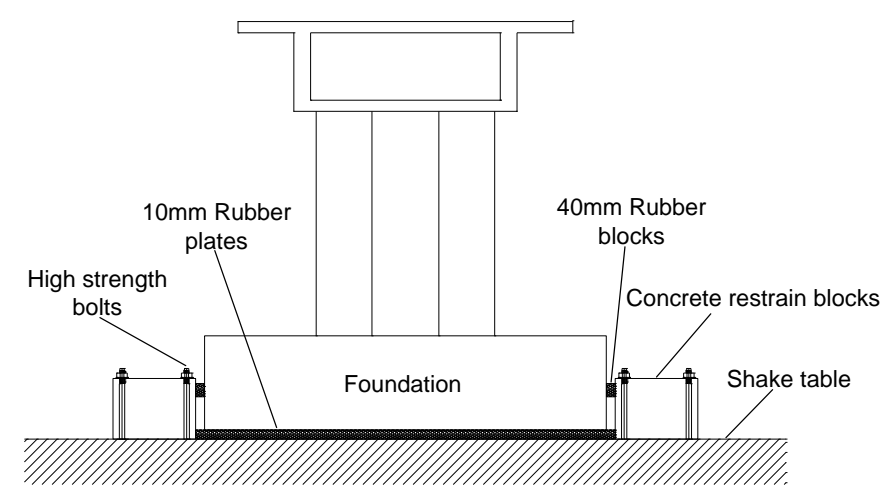

Fig.3 Details of the rocking foundation

\subsection{Sensor arrangement and test setup}

To conduct experimental studies on the seismic responses of extended structures such as bridges under non-uniform ground motions, a shake table array system is required. This experiment was carried out by using the shake table array system at National Engineering Laboratory of High Speed Railway Construction in Central South University, China. The shake table array system includes two 6-DOF shake tables, each with a frequency range of 0.1-50 Hz, payload capacity of 30 tones and size of $4 \times 4 \mathrm{~m}$. When the tables run with the full payload capacity, the maximum acceleration can reach $0.8 \mathrm{~g}$ and $1.6 \mathrm{~g}$ in the horizontal and vertical directions, respectively. During the tests, the bridge responses such as the relative displacement between bridge girders, absolute displacement at the top of piers, accelerations, and the curvature in the piers were measured. Figure 1 illustrates the sensor instrumentation details.

As the primary objective of the experiment is to investigate pounding damage, more sensors were placed at the expansion joint. Four accelerometers were placed at the joint corners in the 
longitudinal direction of each frame to record the acceleration time histories. Additionally, four and two accelerometers were also placed in transverse and vertical directions, respectively. Two LVDTs were placed at the two corners of the deck to measure the relative displacement at the joint as shown in Figure 4.

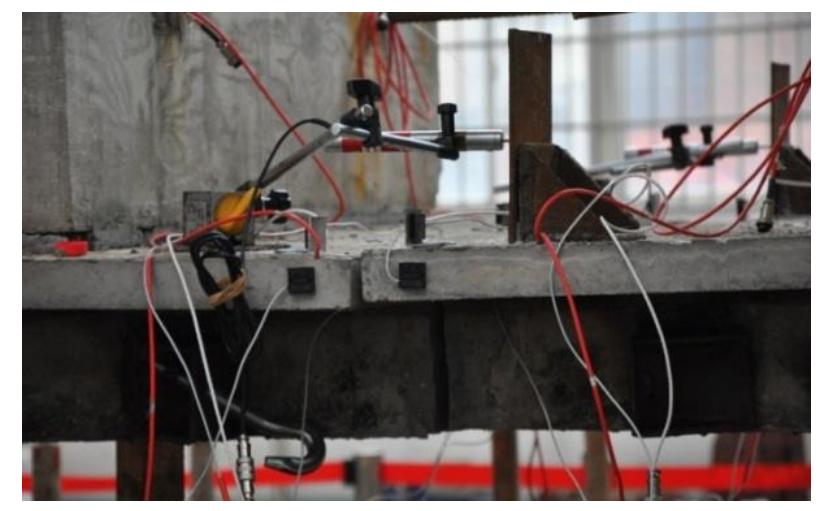

Fig.4 Picture of instrumentation at bridge joint

The pier curvatures of both frames at the top and bottom plastic hinge locations were also measured during the tests. The method for the pier curvature measurements (Johnson 2006) is as shown in Figure 5 by using a pair of LVDTs, which were attached to $16 \mathrm{~mm}$ diameter rods embedded into the concrete. Based on this method, pier curvatures $\kappa$ can be calculated from following equations

$$
\left\{\begin{array}{l}
\kappa=\frac{\alpha}{H} \\
\alpha=\frac{\delta_{1}-\delta_{2}}{L}
\end{array}\right.
$$

where $\delta_{1}, \delta_{2}$ are the displacements from the two transducers, $L$ is the distance between two extension transducers, $H$ is the height between rod and top/bottom of footing/girder. In this study, $L=55.8 \mathrm{~cm}, H=8 \mathrm{~cm}$. In addition, five LVDTs were installed at the top of piers to record the absolute displacement in both longitudinal and transverse directions. A LVDT was attached to each footing corner in the vertical direction to measure the uplifting displacement under rocking foundation condition. A total of 80 channels were used in the tests. 


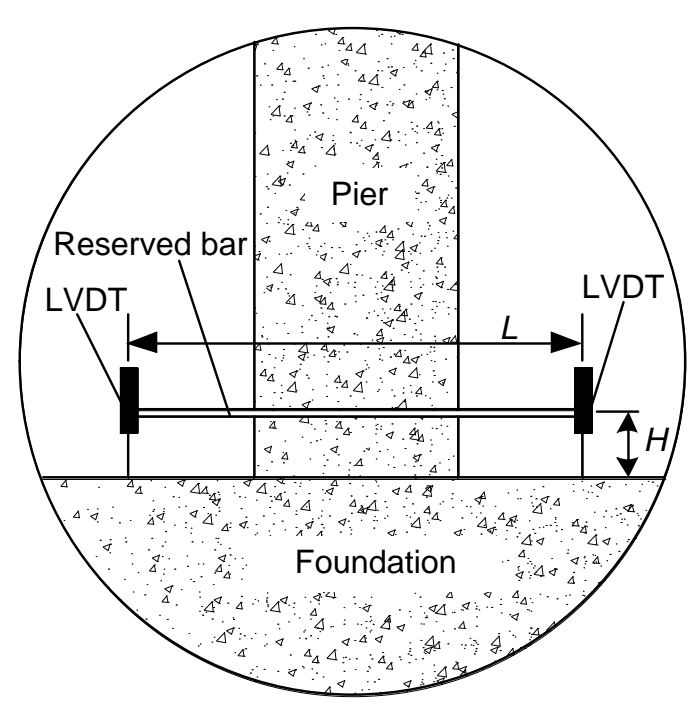

Fig.5 Pier curvature measurement method

\section{Spatially varying ground motions and experimental cases}

\subsection{Spatially varying ground motions}

It is common in engineering practice to simulate spatially varying ground motions that are compatible with the specific design response spectra. Many stochastic ground motion simulation methods have been proposed by different researchers. For example, Hao et al. (1989) and Deodatis (1996) simulated the spatially varying ground motions in two steps: firstly the spatially varying ground motion time histories were generated using an arbitrary power spectral density function, and then adjusted through iterations to match the target response spectrum. Usually a few iterations are needed to achieve a reasonable good match. More recently, Bi and Hao (2012) further developed this method. Instead of using arbitrary power spectral density (PSD) functions, the PSDs that are derived from the response spectra are used. Less or even no iteration is needed in the proposed method. The method proposed by $\mathrm{Bi}$ and Hao (2012) was adopted in the present study to simulate the spatially varying ground motion time histories that are compatible with the design spectra specified in the Chinese Guideline for Seismic Design of Highway Bridge (JTG/T B02-01-2008 2008). 
The spatial variation properties between ground motions recorded at two locations $j$ and $k$ on ground surface is modeled by an empirical coherency loss function (Sobzcky 1991)

$$
\begin{aligned}
\gamma_{j k}(i \omega) & =\left|\gamma_{j k}(i \omega)\right| \exp \left(-\mathrm{i} \omega d_{j k} \cos \alpha / v_{a p p}\right) \\
& =\exp \left(-\beta \omega d_{j k}^{2} / v_{a p p}\right) \cdot \exp \left(-\mathrm{i} \omega d_{j k} \cos \alpha / v_{a p p}\right)
\end{aligned}
$$

where $\beta$ is a coefficient reflecting the level of coherency. $\beta=0.0004,0.0008,0.0016$ are considered in the present study, which represent highly, intermediately, weakly correlated ground motions, respectively. $d_{j k}$ is the distance between two locations $j$ and $k$ in the wave propagation direction, $\omega$ is the circular frequency in $\mathrm{rad} / \mathrm{s} . v_{a p p}$ is the apparent wave velocity, measuring the time delay between ground motions at two supports $j$ and $k$ separated by distance $d_{j k}$. $\alpha$ is the seismic wave incident angle. In the present study, $v_{a p p}$ is assumed to be $500 \mathrm{~m} / \mathrm{s}$, and $\alpha=60^{\circ}$.

To study the influence of different local site conditions, three different sites, i.e. strong rock site (Class I), medium-soft soil site (Class III), and soft soil site (Class IV) are considered based on the Chinese Guideline for Seismic Design of Highway Bridge. The characteristic periods for the sites are $0.3,0.55$, and $0.75 \mathrm{~s}$ respectively. Totally five ground motion cases representing different local site conditions and ground motion spatial variations are simulated and they are listed in Table 2. In the simulations, the sampling and upper cut-off frequencies were set to 100 and $25 \mathrm{~Hz}$, respectively. Duration of 20.48 s was selected to have a convenient total number of 2048 points.

Figure 6 shows one set of the simulated ground motion time histories (MC5). Figure 7 compares the response spectra of the simulated ground motions and the target design spectra. All of the acceleration spectra are normalized to $1.0 \mathrm{~g}$ and $5 \%$ damping. It is demonstrated that the simulated ground motions match well with the target design spectra. Figure 8 shows the comparison between the coherency loss of the simulated motions and the empirical coherency 
loss function. Good matches are observed again.

It should be noted that bi-directional excitations were considered in the present study. In the lateral direction, the ground motion intensity and coherency condition were the same as that in the longitudinal direction but they were independently simulated, in other words, the longitudinal and lateral motions are independent with each other. It is also noted that to account for scaling effect, all the simulated ground motions were modified according to the similarity ratio provided in Table 1 . As such, the duration of the input motions is compressed to $20.48 / 2.45=8.359 \mathrm{~s}$.

Table 2 Cases of spatially varying ground motions

\begin{tabular}{ccc}
\hline Motion Cases No. & Site Condition & Coherency \\
\hline MC1 & III & Highly $(\beta=0.0004)$ \\
MC2 & III & Intermediately $(\beta=0.0008)$ \\
MC3 & III & Weakly $(\beta=0.0016)$ \\
MC4 & I & Intermediately $(\beta=0.0008)$ \\
MC5 & IV & Intermediately $(\beta=0.0008)$ \\
\hline
\end{tabular}

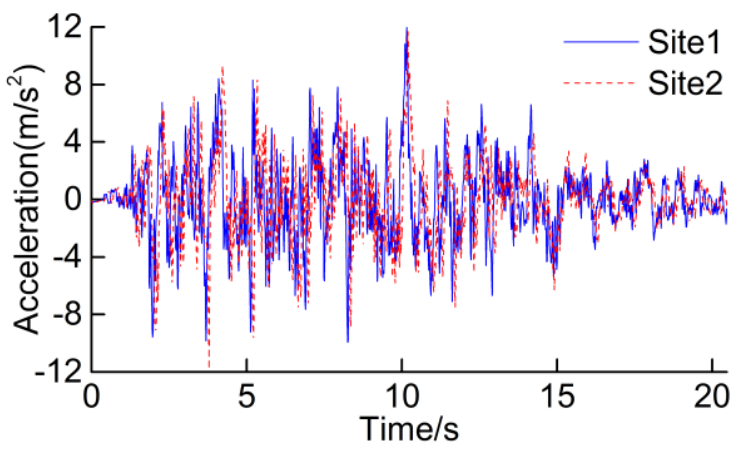

(a)

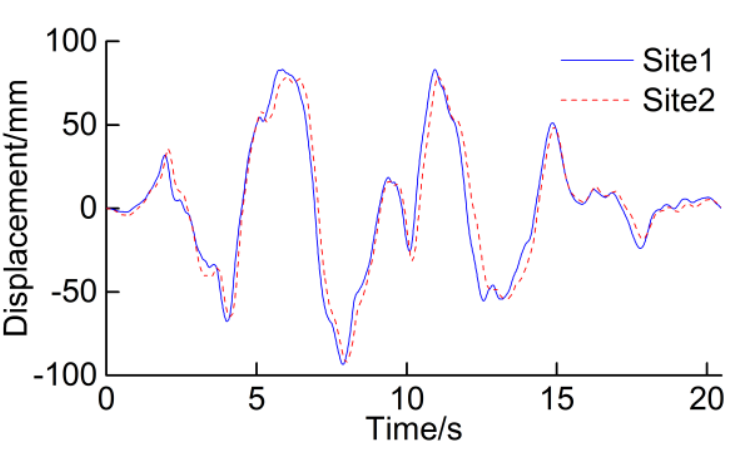

(b)

Fig.6 Simulated ground motions. (a) Accelerations (b) Displacements 


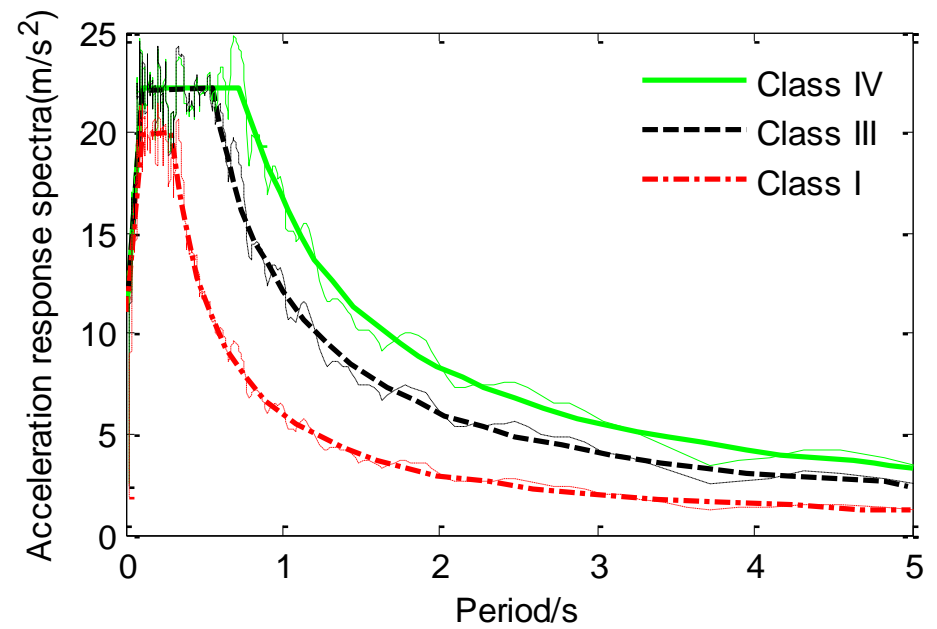

Fig.7 Comparison of the response spectra of the simulated ground motions (thin lines) and the target design spectra (bold lines)

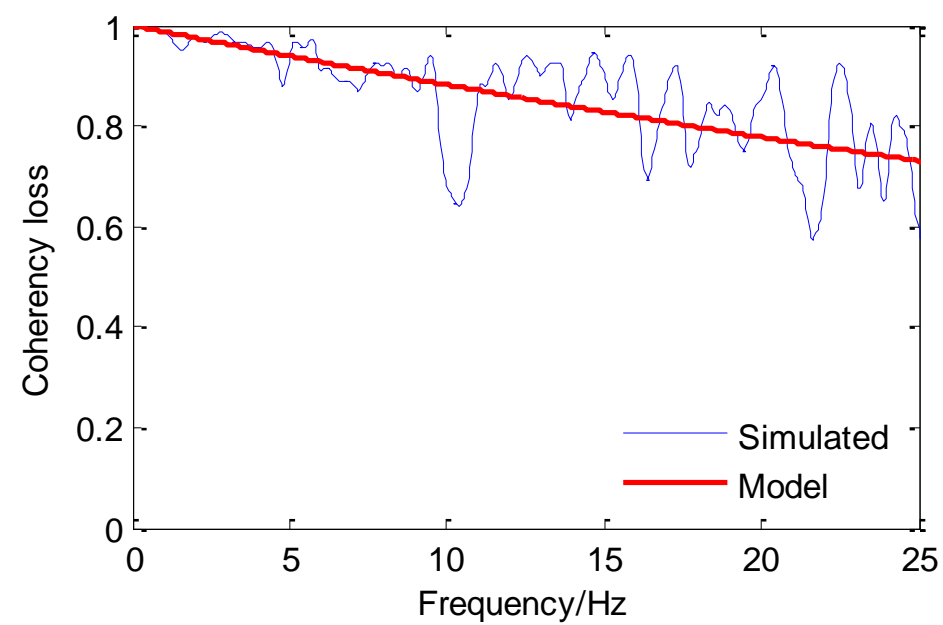

Fig.8 Comparison of coherency loss function

\subsection{Experimental cases}

During the tests, the model with rocking foundation was excited by uniform excitation, non-uniform excitations with time delay, and spatially varying excitations under a low intensity of $0.25 \mathrm{~g}$. The same tests were also carried out on the models with fixed foundation to study the influence of the foundation types on the pounding responses. In addition to the low intensity tests, the fixed foundation model was also tested under the gradually increasing ground motion intensities from $0.25 \mathrm{~g}$ to $0.75 \mathrm{~g}$. During the high intensity cases, two concrete masses blocks are removed from Frame 2, resulting in a period ratio $\left(\mathrm{T}_{1} / \mathrm{T}_{2}\right)$ of 1.1. The 
ground motion MC5 were scaled to various intensity levels and were used as inputs for high intensity tests. The considered experimental cases are summarized in Table 3. For the uniform input case, the motions for Frame 1 were applied to both tables.

Table 3 Test cases

\begin{tabular}{|c|c|c|c|c|c|}
\hline \multicolumn{2}{|c|}{ Rocking Foundation } & \multicolumn{4}{|c|}{ Fixed Foundation } \\
\hline Case No. & Motion & Case No. & Motion & Case No. & Motion \\
\hline RL1 & Uniform $0.25 \mathrm{~g}$ & FL1 & Uniform $0.25 \mathrm{~g}$ & FH1 & Uniform $0.25 \mathrm{~g}$ \\
\hline RL2 & $\begin{array}{c}\text { Time delay } \\
0.25 \mathrm{~g}\end{array}$ & FL2 & $\begin{array}{c}\text { Time delay } \\
0.25 \mathrm{~g}\end{array}$ & $\mathrm{FH} 2$ & MC5 $0.25 \mathrm{~g}$ \\
\hline RL3 & MC1 $0.25 \mathrm{~g}$ & FL3 & MC1 $0.25 \mathrm{~g}$ & FH3 & Uniform $0.4 \mathrm{~g}$ \\
\hline RL4 & $\mathrm{MC} 20.25 \mathrm{~g}$ & FL4 & MC2 $0.25 \mathrm{~g}$ & FH4 & MC5 0.4g \\
\hline RL5 & MC3 $0.25 \mathrm{~g}$ & FL5 & MC3 $0.25 \mathrm{~g}$ & FH5 & MC5 $0.5 \mathrm{~g}$ \\
\hline RL6 & MC4 $0.25 \mathrm{~g}$ & FL6 & MC4 $0.25 \mathrm{~g}$ & FH6 & MC5 $0.6 \mathrm{~g}$ \\
\hline RL7 & MC5 $0.25 \mathrm{~g}$ & FL7 & MC5 $0.25 \mathrm{~g}$ & FH7 & MC5 $0.75 \mathrm{~g}$ \\
\hline
\end{tabular}

\section{Numerical model}

LS-DYNA, a general purpose FE software, is used to undertake a numerical simulation of the experiment proposed in Section 2. For validation purpose, only Case FH4 was simulated in the numerical study.

\subsection{Element, contact and boundary conditions}

Figure 9(a) shows the detailed finite element model. The constant stress solid elements are employed for all the concrete members. To realistically simulate pounding induced damage, fine meshes are required. On the other hand, this will significantly increase the computational effort. To balance the computation time and accuracy, the bridge model is divided into different regions with different mesh sizes since pounding induced damage is highly localized, the detailed modeling with a fine mesh size of $12.5 \mathrm{~mm}$ is only applied to a length of $0.25 \mathrm{~m}$ from the end of bridge girders. Along a length of $0.35 \mathrm{~m}$ near the top of the piers and the central portion of bridge deck beyond $0.25 \mathrm{~m}$ from the edge of bridge girder are meshed by 25 
$\mathrm{mm}$ elements. Beyond these regions, the mesh size of the girder in the longitudinal direction is $200 \mathrm{~mm}$. $20 \mathrm{~mm}$ and $50 \mathrm{~mm}$ mesh sizes are adopted in the modeling of the piers and the footing, respectively.

Belytschko beam elements are used to simulate the pre-stressing tendons and the reinforcement bars in the pounding prone regions. The connections between concrete and reinforcement or tendons are modeled by sharing the same nodes based on completely rigid connection assumption. The RC smeared models (i.e. reinforcement is assumed to be uniformly distributed over concrete element) are used to simulate concrete at the piers and the places sufficiently away from the pounding prone regions of the girders. Figure 9(b) shows the detailed (fine) meshes around the expansion joint. The lumped mass elements are used to model the additional masses on the top of the decks. Due to the considerable size of the concrete blocks as shown in Figure 2, the nodes of the mass elements are located at the actual center-of-gravity of the additional blocks and connected to the corresponding nodes on the decks by using the nodal displacement master-slave constraint.

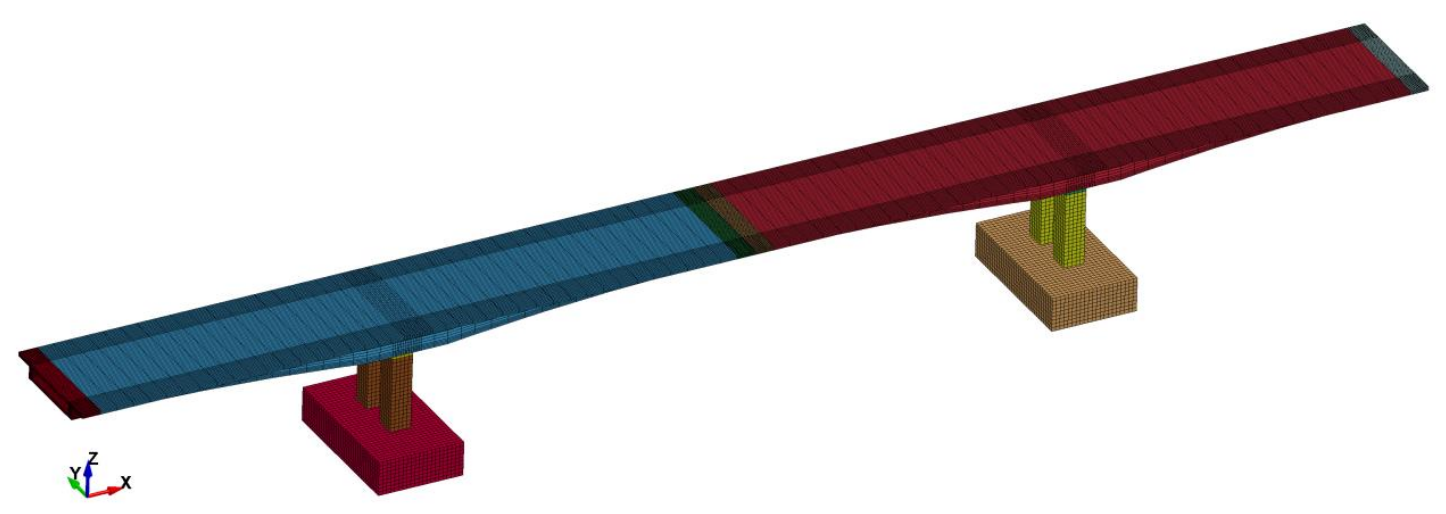

(a) 


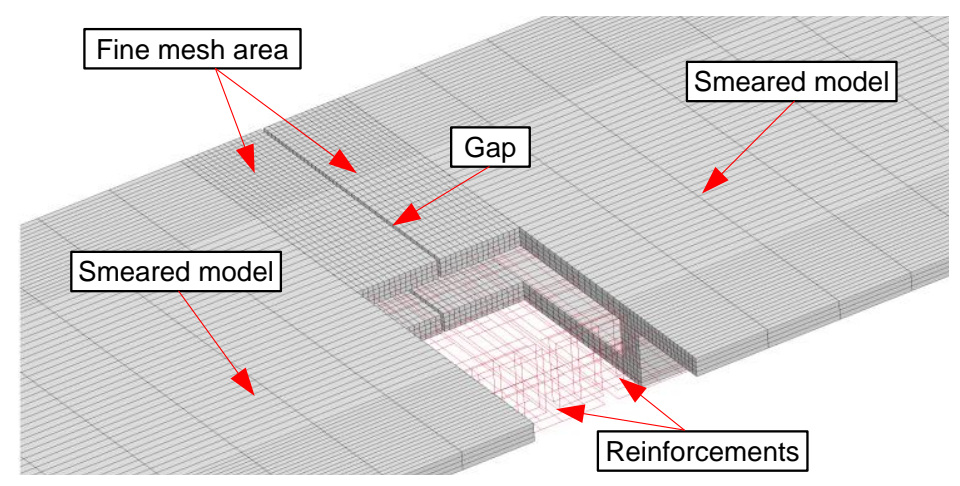

(b)

Fig.9 Finite element model of the tested bridge: (a) The overall view, (b) Detailed meshing at the joint

Pounding may occur at the entire interfaces of the girder ends with sticking or sliding in the tangential direction of the contact interface. In this study, the contact algorithm *CONTACT_AUTOMATIC_SURFACE_TO_SURFACE in LS-DYNA is defined between the adjacent decks to describe the pounding effect. In the tangential direction of the contact interface, an approximation of the Coulomb friction model (i.e. arctangent model) is adopted to represent the relationship between the normal stress and the tangential stress. The dynamic and static Coulomb friction values are both set to 0.5 in the present study (Bi and Hao, 2013; Jankowski 2009). To represent the actual restraint condition of the fixed foundation, the base of the footing is fixed in the vertical direction in the model. Ground motions recorded at the table during the test are applied to the base of the footing at the longitudinal and transverse directions in the form of displacement by using the *LOAD_CURVE keyword in LS-DYNA.

\subsection{Material model}

The material model *MAT_CONCRETE_REL3 (*MAT_72REL3), *MAT_PSEUDO_Tensor (*MAT_16), and *MAT_ELASTIC (*MAT_1) available in LS-DYNA are used to model the concrete at different regions in this study. The advantage of *MAT_72REL3 and *MAT_16 material models is that they can automatically generate the model parameters by specifying 
the density, Poisson's ratio and unconfined compressive strength. *MAT_72REL3 model is applied for the concrete at the pounding prone areas. *MAT_16 model is a smeared RC material model. It is used to model smeared concrete of the pier and at the remaining places of the girders. In this study, the unconfined compressive strengths of superstructure and substructure are obtained from the experiments as $45 \mathrm{MPa}$ and $35 \mathrm{MPa}$, respectively and they are used in LS-DYNA. The footings are simply modeled by elastic material (*MAT_1) to save the computational effort.

In order to avoid computer overflow during calculation, the *MAT_ADD_EROSION card is used to eliminate elements that do not further contribute to resisting the impact loads during the analysis. Erosion technique is commonly used to delete elements experiencing large deformations by setting one or more erosion criterion, e.g. principal stress/strain, tensile stress, and shear strain et.al. It is noted that erosion is only a numerical manipulation to avoid mesh tangling and has no physical meaning. It removes the concrete materials, and meanwhile, violates the mass conservation of the structure. Therefore, erosion should be used with caution (Tang and Hao 2010). In the present study, the concrete mesh will be deleted when the maximum principal strain reaches 0.15 (Bi and Hao 2013).

The elastic-plastic material model *MAT_PIECEWISE_LINEAR_PLASTICITY (*MAT_24) is employed for the steel reinforcements in the bridge girder. The advantage of these material models is that they allow users to define arbitrary stress-strain curves. A temperature dependent material *MAT_ELASTIC_PLASTIC_THERMAL (*MAT_4) is selected to model the pre-stress tendons in the bridge girder based on the thermal shrinkage method. In order to load a pre-stress force in the girders, the card *LOAD_THERMAL_LOAD _CURVE is used to define a negative nodal temperature. The parameters of all the materials used in this study are tabulated in Table 4. 
Table 4 Material properties

\begin{tabular}{llll}
\hline Material & LS-DYNA model & Parameter & Value \\
\hline $\begin{array}{l}\text { Concrete } \\
\text { (Pounding prone area) }\end{array}$ & *MAT_CONCRETE_DAMAGE_REL3 & Mass density & $2400 \mathrm{~kg} / \mathrm{m}^{3}$ \\
& $(*$ MAT_72REL3) & Poisson's ratio & 0.3 \\
Concrete & Compressive strength & $45 \mathrm{MPa}$ \\
(Smeared concrete on girders) $)$ & $(*$ MAT_PSEUDO_Tensor & Mass density & $2500 \mathrm{~kg} / \mathrm{m}^{3}$ \\
& & Poisson's ratio & 0.3 \\
& & Compressive strength & $45 \mathrm{MPa}$ \\
Concrete & $*$ MAT_PSEUDO_Tensor & Percent reinforcement & $2.00 \%$ \\
(Piers) & $(*$ MAT_16) & Mass density & $2500 \mathrm{~kg} / \mathrm{m}^{3}$ \\
& & Poisson's ratio & 0.3 \\
& & Compressive strength & $35 \mathrm{MPa}$ \\
Concrete & & Percent reinforcement & $1.23 \%$ \\
(Footings) & DMAT_ELASTIC & Density & $2500 \mathrm{~kg} / \mathrm{m}^{3}$ \\
& $(*$ MAT_1) & Young's modulus & $31.5 \mathrm{GPa}$ \\
Steel & & Poisson's ratio & 0.2 \\
(Pounding prone area) & $*$ MAT_PIECEWISE_LINEAR_PLASTICITY & Density & $7850 \mathrm{~kg} / \mathrm{m}^{3}$ \\
& $(*$ MAT_24) & Young's modulus & $200 \mathrm{GPa}$ \\
& & Poisson's ratio & 0.3 \\
& & Yield stress & $400 \mathrm{MPa}$ \\
Pre-stress tendons & & Tangent modulus & $1600 \mathrm{MPa}$ \\
& & Failure strain & 0.01 \\
& & Density & $7850 \mathrm{~kg} / \mathrm{m}^{3}$ \\
& & Young's modulus & $195 \mathrm{GPa}$ \\
& & Poisson's ratio & 0.3 \\
& & Coefficients of thermal expansion & $1.2 \times 10^{-5}$ \\
\hline
\end{tabular}

\subsection{Strain rate effect}

For reinforced concrete structures subjected to impact loads (i.e. at high strain rates), the apparent strength of concrete and steel materials can be increased significantly. Therefore, the strain rate effect needs to be taken into account to reliably predict the structural responses. The effect of strain rate on the material strengths is typically considered by the Dynamic Increase Factor (DIF) (i.e. the ratio of dynamic to static strength) The most comprehensive model for strain rate enhancement of concrete both in tension and compression is the bilinear relationship developed by CEB Code (Comité Euro-International du Béton 1993). In tension, the DIF in CEB code of the tensile strength is provided as the following equations 


$$
\left\{\begin{array}{l}
\text { TDIF }=\frac{f_{t}}{f_{t s}}=\left(\frac{\dot{\varepsilon}}{\dot{\varepsilon}_{t s}}\right)^{1.016 \delta} \text { for } \dot{\varepsilon} \leq 30 s^{-1} \\
T D I F=\frac{f_{t}}{f_{t s}}=\beta\left(\frac{\dot{\varepsilon}}{\dot{\varepsilon}_{t s}}\right)^{1 / 3} \text { for } \dot{\varepsilon}>30 s^{-1} \\
\delta=\frac{1}{10+6 f_{c s} / f_{c o}} \\
\log \beta=7.112 \delta-2.33
\end{array}\right.
$$

where $f_{t}$ is the dynamic tensile strength at strain rate $\dot{\varepsilon}$ in the range of $30 \times 10^{-6}$ to $300 s^{-1} . f_{t s}$ is the static tensile strength at $\dot{\varepsilon}_{t s}$, while $\dot{\varepsilon}_{t s}$ is the static strain rate and taken as $30 \times 10^{-6} s^{-1} . f_{c s}$ is the static compressive strength at $\dot{\varepsilon}_{t s}$ and $f_{c o}$ is taken as $10 \mathrm{MPa}$. Based on CEB code, the DIF for the compressive strength is given as follows

$$
\left\{\begin{array}{l}
C D I F=\frac{f_{c}}{f_{c s}}=\left(\frac{\dot{\varepsilon}}{\dot{\varepsilon}_{c s}}\right)^{1.026 \alpha} \text { for } \dot{\varepsilon} \leq 30 s^{-1} \\
C D I F=\frac{f_{c}}{f_{c s}}=\gamma\left(\frac{\dot{\varepsilon}}{\dot{\varepsilon}_{c s}}\right)^{1 / 3} \text { for } \dot{\varepsilon}>30 s^{-1} \\
\alpha=\frac{1}{5+9 f_{c s} / f_{c o}} \\
\log \gamma=6.156 \delta-2
\end{array}\right.
$$

where $f_{c}$ is the dynamic tensile strength at strain rate $\dot{\varepsilon}$ in the range of $30 \times 10^{-6}$ to $300 s^{-1}$.

The DIF model for steel reinforcing bars proposed by Malvar (1998) is utilized in the present study to consider the strain rate effect on the reinforcements as follows

$$
\left\{\begin{array}{l}
D I F=\left(\frac{\dot{\varepsilon}}{10^{-4}}\right)^{\alpha} \\
\alpha=0.074-0.040 f_{y} / 414
\end{array}\right.
$$

where $f_{y}$ is the steel yield strength in MPa.

\section{Experimental and numerical results}

The experimental results, including the data recorded from the sensors, and bridge damages observed after each experimental case, are investigated in this section. Analysis and comparisons are carried out based on these results to study the pounding response, the effect 
of spatially varying ground motions and the effect of foundation rocking. The comparison between the experimental and numerical results is also conducted in this section.

\subsection{Pounding responses}

Pounding always lead to the large collision force, severe vibration of the bridge decks, and a sudden velocity exchange between the two neighboring decks, which results in large impulses in the acceleration time histories (Guo et al. 2011). Therefore, acceleration measurement from the accelerometers placed at the expansion joint of the bridge model are used in this study to identify the pounding occurrence. The amplitude of the acceleration pulses is a direct reflection of the intensity of pounding forces. From the numbers and the instances of the sharp peaks in the acceleration histories, the collision numbers and time can be found. However, when the impact force is not large enough, the corresponding impulses might be easily smeared by the acceleration response of structure and the mechanical noises. This phenomenon will result in the missing of some pounding events. To overcome this problem, this paper proposes using wavelet transform method to identify the occurrence of impact.

Wavelet transform is very effective to analyze the signal singularity and scale with an excellent time-frequency localization property. The wavelet transform of a one-dimensional signal $f(t)$ is described as an integral form that convolutes the signal with the wavelet basis function $\psi(t)$ called the mother wavelet (Ren et al. 2013)

$$
W_{f}(a, b)=\frac{1}{\sqrt{|a|}} \int_{R} f(t) \overline{\psi\left(\frac{t-b}{a}\right)} d t
$$

The mother wavelet $\psi(t)$ should meet the admissible condition

$$
C_{\psi}=\int_{R} \frac{|\hat{\psi}(\omega)|^{2}}{|\omega|} d \omega<\infty
$$

where $\hat{\psi}(\omega)$ is the Fourier transform of the mother wavelet $\psi(t) . W_{f}(a, b)$ is called the wavelet coefficients and employed in this study to determine the occurrence of pounding for 
the experimental data. There may exist abrupt changes of wavelet coefficients with respect to the frequency at the time of pounding. The changes in frequency contents indicate the magnitude of the pounding force. The complex Morlet wavelet with a central frequency of 1.0 $\mathrm{Hz}$ and bandwidth of $1.5 \mathrm{~Hz}$ is chosen as the mother wavelet for this research, since Morlet wavelet is similar to impulse component (Xing et al. 2012).

Taking Case FH4 as an example, Figure 10 presents the absolute longitudinal accelerations recorded by accelerometers J4 and J6 (Figure 1) and the corresponding scalogram. As shown in Figure 10(a), it is observed that two obvious impulses appear at 4.095 and $5.875 \mathrm{~s}$, in the absolute acceleration histories, and the peak values are about 2 times as those of other time ranges. A slight impulse is also observed at $1.650 \mathrm{~s}$, but the peak value only presents very slight increase and is not easily observable. However, after applying wavelet transform to the recorded acceleration time history, the wavelet coefficients at all these instants show very obvious difference compared to other times. The coefficients are about four times as those at other times. The pounding at 1.650 s is clearly identified by using this method. Similarly, the same analysis is applied to the longitudinal acceleration recorded by accelerometer J6 at Frame 2 (Figure 10(b)). The same pounding instants are identified again..

Some sharp peaks are visible in the time-history of the absolute acceleration response in the transverse direction at the corner of bridge deck of Frame 2 recorded by the accelerometer J6 as shown in Figure 11(b). This phenomenon clearly shows that during the collisions there exists an interaction along the transverse direction which may be caused by friction during the contact or the eccentric poundings. However, no obvious impulses are found in Figure 11(a) that presents the acceleration recording of Frame 1. Comparing the transverse acceleration response of Frame 2 with those of Frame 1 indicates that the transverse interaction during the poundings affect the lateral acceleration response of Frame 2 more significantly than Frame 1. 
Therefore, the lateral acceleration pulses should be caused by the oblique impact between adjacent segments more than the friction. This is because that the friction induced acceleration recorded from the decks of two adjacent frames should have the opposite signs according to Malhotra et al.’s work (1995).

For other cases, wavelet transform is applied again as mentioned above, and the pounding times are identified. The pounding times and maximum longitudinal accelerations for the fixed base cases are summarized in Table 5. It is found that the pounding number increases with the intensity of the ground motions. The maximum accelerations, induced by pounding, however, do not necessarily increase with the intensity of the ground motions. Figure 12 shows the experimental results of the maximum values of absolute acceleration from all the fix base cases with different ground motion intensities. It is demonstrated that, for cases without pounding, the longitudinal acceleration responses of stiff frame (Frame 2) are slightly lower than that of flexible one (Frame 1). However, the stiff frame is more sensitive to the collisions than the flexible one when only longitudinal acceleration responses are considered. These conclusions are in agreement with the numerical results of Anagnostopoulos' work (Anagnostopoulos and Spiliopoulos 1992). 

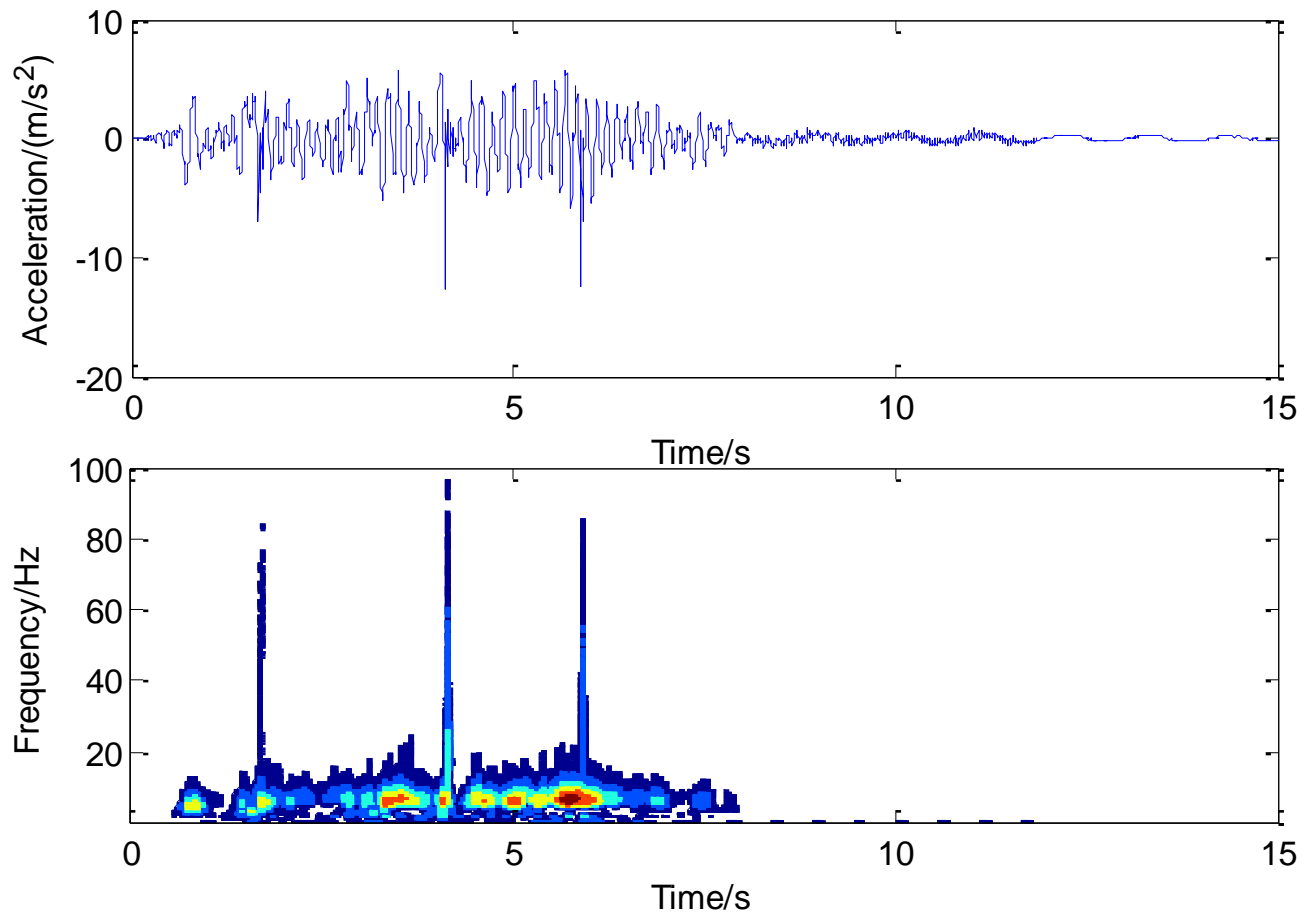

(a)
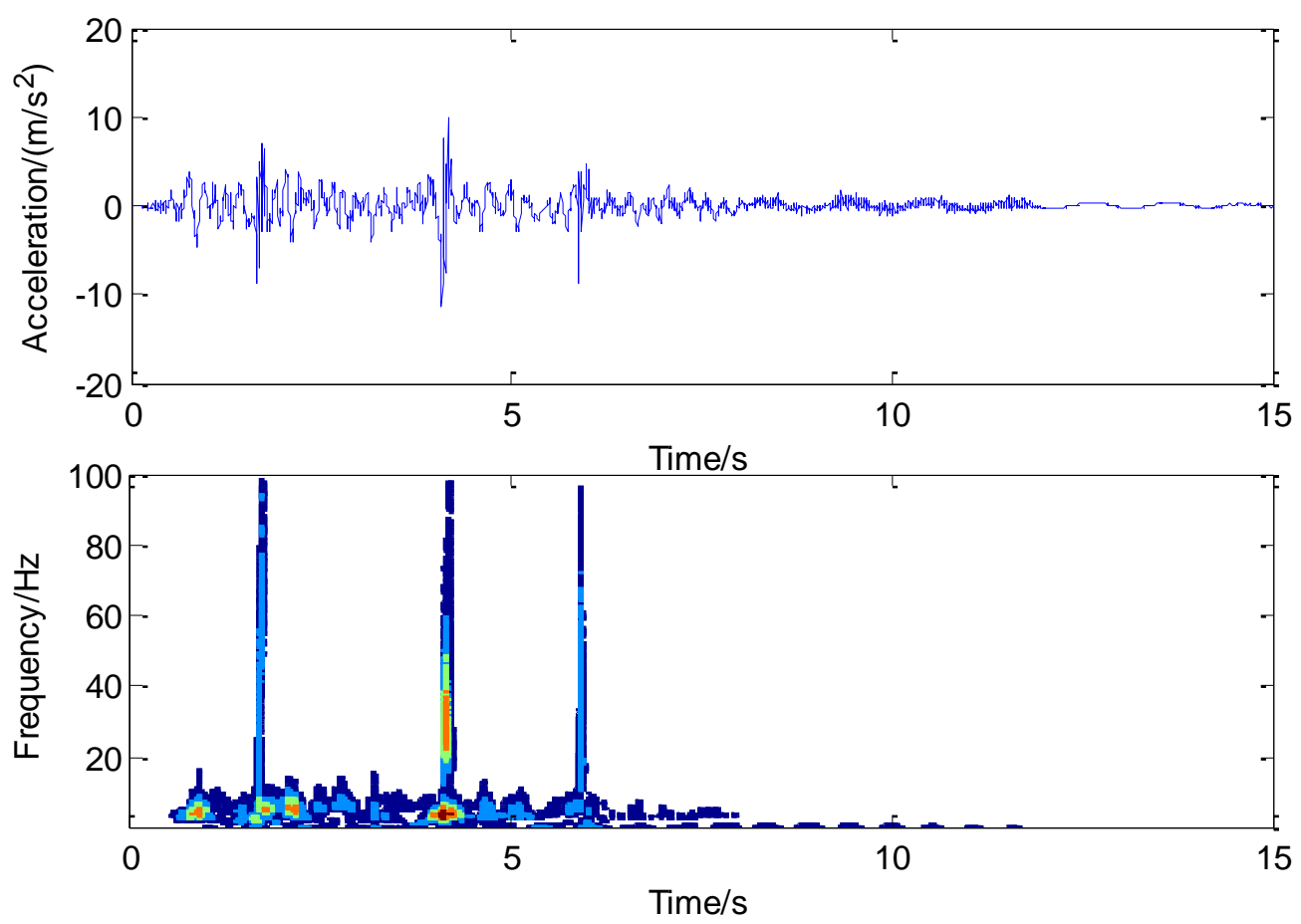

(b)

Fig.10 Time histories and wavelet scalogram of longitudinal accelerations recorded by different accelerometers: (a) J4; (b) J6 


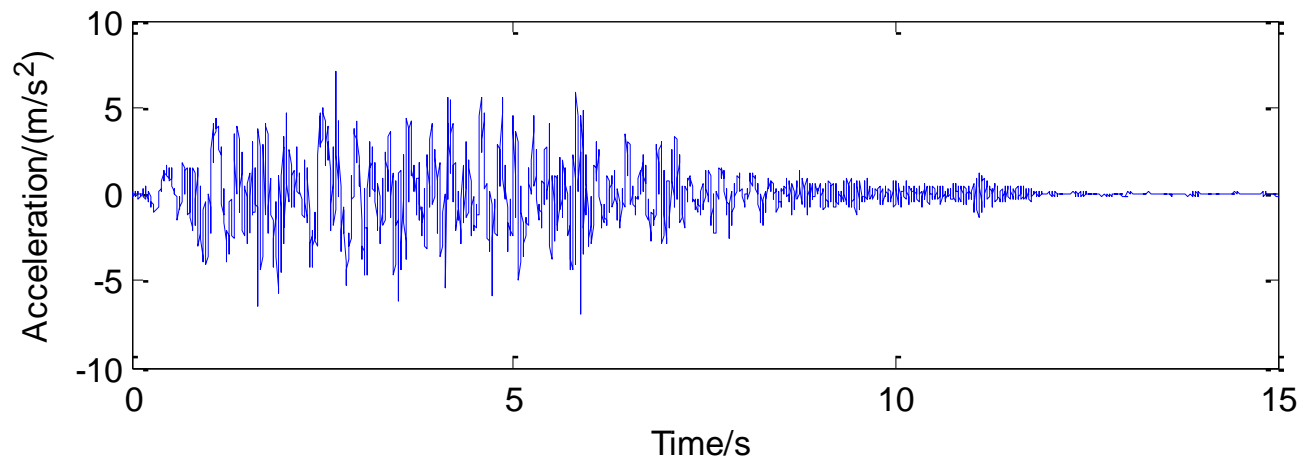

(a)

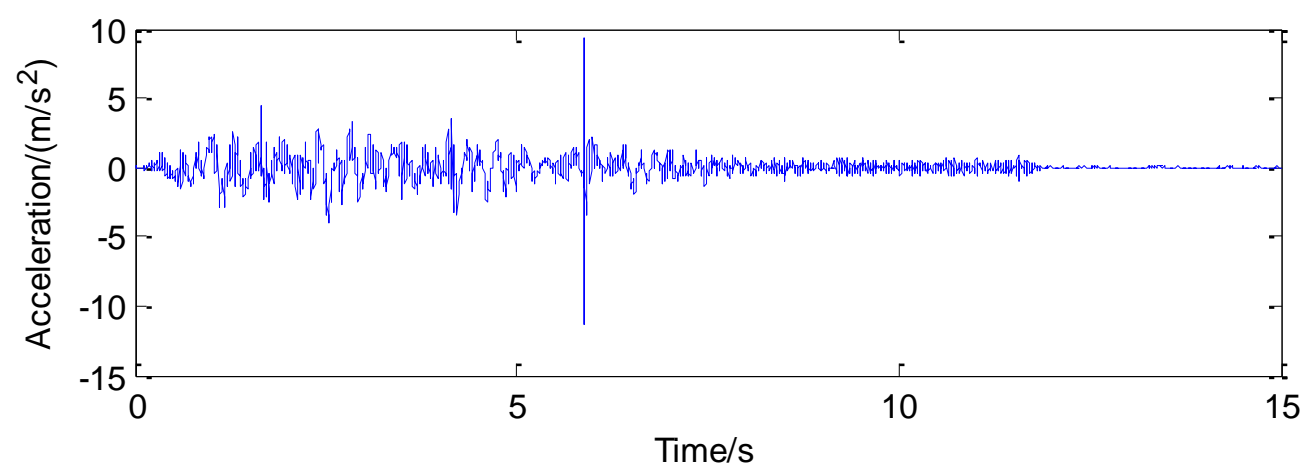

(b)

Fig.11 Time histories transverse acceleration at the joint corners (a) Frame 1; (b) Frame 2

Table 5 Detected pounding times and corresponding peak longitudinal accelerations for the fixed-base cases

\begin{tabular}{cccc}
\hline \multirow{2}{*}{ Case No. } & \multirow{2}{*}{ Number of pounding } & \multicolumn{2}{c}{ Acceleration Peak $\left(\mathrm{m} / \mathrm{s}^{2}\right)$} \\
\cline { 3 - 4 } & & Frame1 & Frame2 \\
\hline FH1 & No pounding & 4.016 & 3.797 \\
FH2 & No pounding & 5.283 & 4.213 \\
FH3 & No pounding & 6.380 & 5.491 \\
FH4 & 3 & 13.00 & 11.82 \\
FH5 & 4 & 9.870 & 12.95 \\
FH6 & 5 & 12.67 & 33.71 \\
FH7 & 7 & 22.98 & 24.06 \\
\hline
\end{tabular}

To investigate the influence of pounding on the seismic responses of bridge girders and piers, The seismic responses from Cases FH3 and FH4 are compared. As shown in Table 5, FH3 
represents a case without pounding while poundings occur in Case FH4. Figure 13 shows the longitudinal acceleration responses of these two cases. It is found that, the acceleration responses agree with each other during most of the time. The accelerations become larger when poundings occur. It also can be seen that the third pounding increases the acceleration response in the time range of nearly one second after collision by almost twice as compared with the results without pounding. However, the first two poundings do not change the pounding responses obviously. This might be explained by the different momentum exchanges and stress wave propagation during the impact.

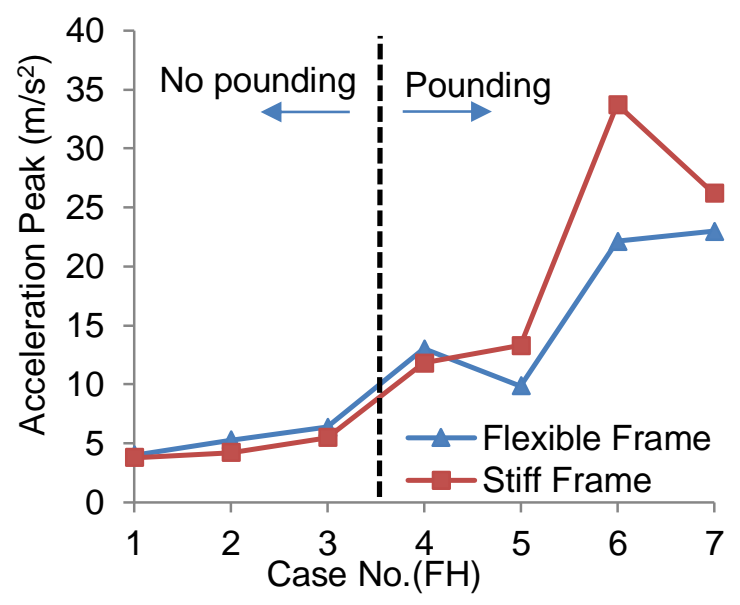

Fig.12 Maximum absolute acceleration of every high intensity cases

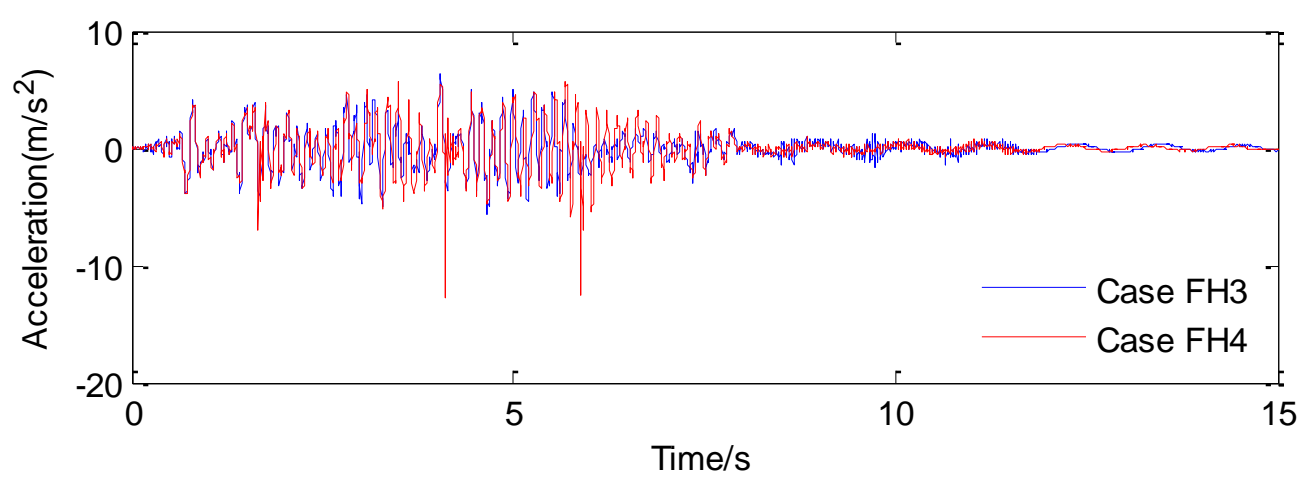

Fig.13 Longitudinal acceleration response with/without pounding

Figure 14 and Figure 15 show the displacement and curvature responses of Pier 1, respectively. It is observed that the former two collisions have a negligible influence on the 
pier response. The third pounding slightly reduces both the displacement response at the top of the pier and the curvature response at the base of the pier. For this particular case, pounding seems to be beneficial for the response of bridge substructures. However, this result may not represent the universal law, pounding could result in response amplifications if the colliding bridge segments have significantly different fundamental period (Kim and Shinozuka 2003). However, it is also necessary to note that prevailing design codes (such as, Caltrans 2010) do not allows construction of bridge segments with significantly different fundamental period.

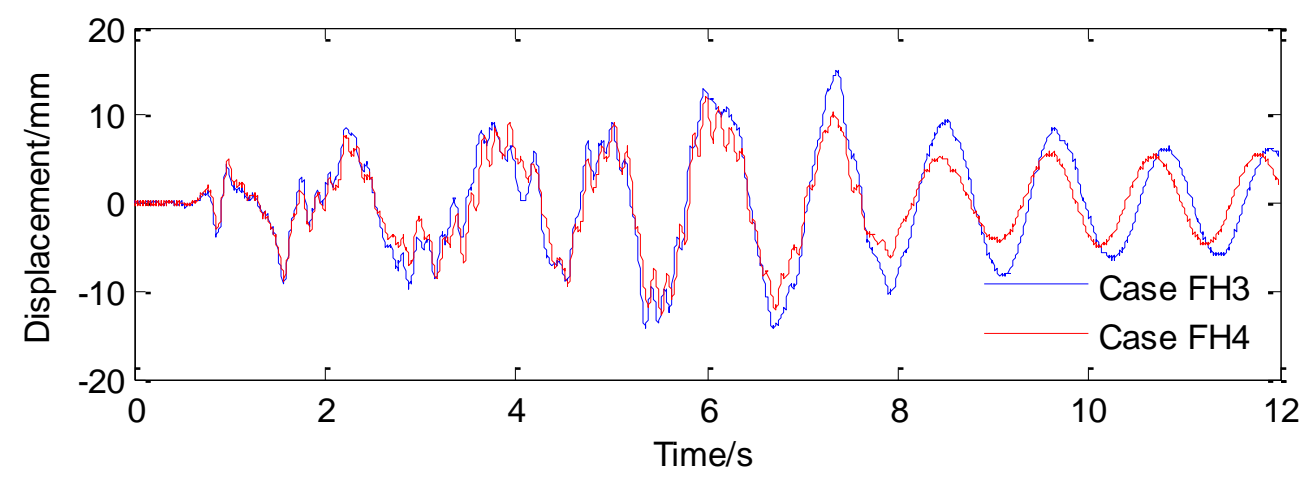

Fig.14 Time history of displacement at the top of Pier 1

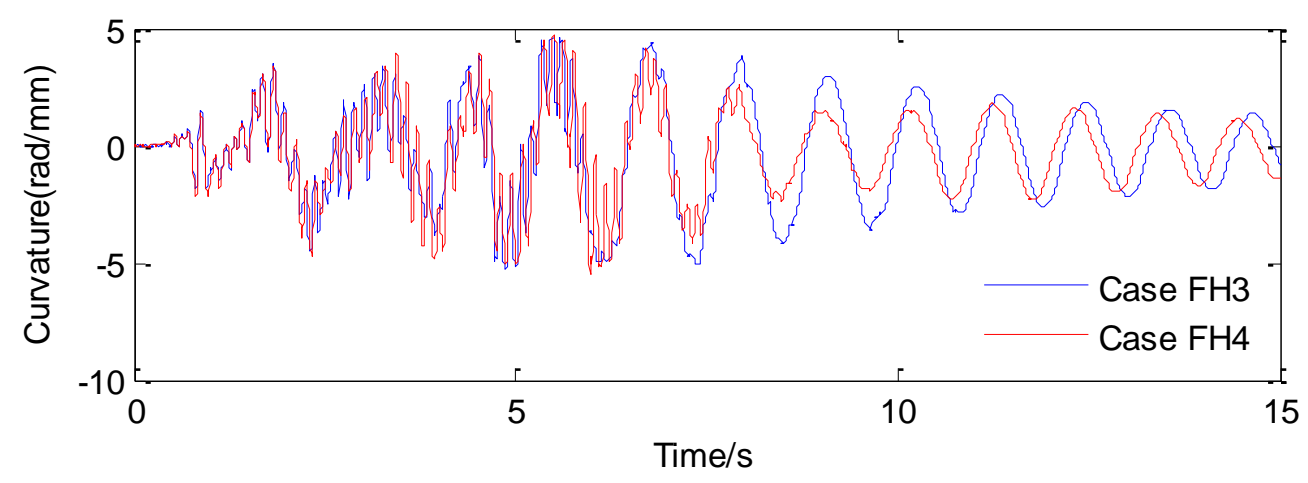

Fig.15 Time history of curvature at the base of Pier 1

Figure 16 shows the local damage pattern of the bridge decks at the joint during Cases FH4 and FH7. As shown in Figures 16(a) and (b), after Case FH4 a wide range of cover concrete spalling and top layer steel bar explosions were observed. The areas of the concrete spalled from Frame 1 and Frame 2 are about $0.12 \mathrm{~m}$ x $0.1 \mathrm{~m}$ and $0.16 \mathrm{~m}$ x $0.12 \mathrm{~m}$, respectively. Slight 
concrete spalling was also observed at the end girder of both decks on the south side as presented in Figure 16 (b).

After Case FH7, according to Figures 16(c), the concrete spalling at the deck of Frame 2 were extended to a wider area with a size of $0.45 \mathrm{~m} \times 0.15 \mathrm{~m}$, and more steel bars were exposed. The concrete at the center of deck of Frame 1 was severely crushed within a large area of $0.3 \mathrm{~m} \times 0.1 \mathrm{~m}$. Except for concrete crushing and spalling damages, a permanent dislocation with a length of $0.04 \mathrm{~m}$ in the lateral direction was also observed between two adjacent decks at the joint as shown in Figure 16(d). The dislocation was caused by the large relative displacements in the transverse direction induced by the lateral ground excitations.

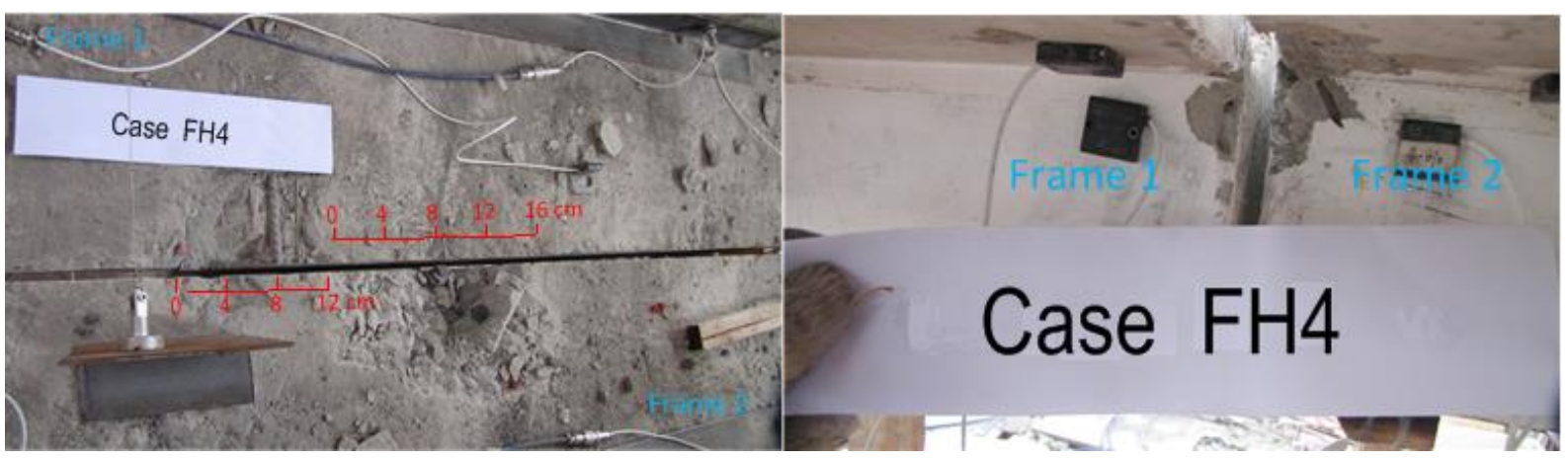

(a)

(b)

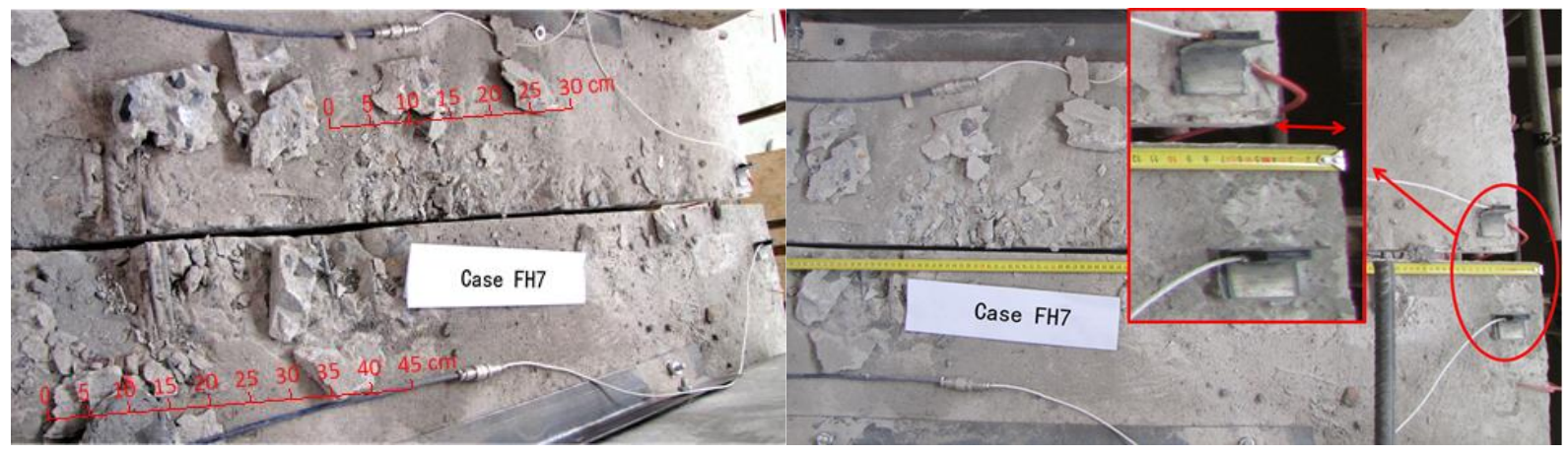

(c)

(d)

Fig.16 Pounding damages, (a), (b) Case FH4, (c), (d) Case FH7

\subsection{Effect of spatially varying ground motions}

Previous studies revealed that spatially varying ground motions can have a significant 
influence on the bridge responses and pounding responses. To investigate this effect, the results obtained from Case RL1 to RL7 are compared with each other. Figure 17(a) shows the time histories of relative displacements between two decks at the joint when the two frames subjected to uniform ground motions (Case RL1), 0.041s time delayed ground motions (Case RL2), and spatially varying ground motions with a high coherency (Case RL3). It can be observed that the spatially varying ground motions resulted in the largest relative displacements (the black line)on both positive (closing) and negative (opening) directions.. The relative displacement response in the Case RL2 (the red line) was far larger than the results (the blue line) due to uniform excitations (Case RL1).

Table 6 lists the detected pounding events in all low intensity cases $(0.25 \mathrm{~g})$. Comparing the results of Cases RL1 to RL3 revealed that the excitations considering time delay could result in poundings and large acceleration peaks. The spatially varying excitations can result in the greater acceleration peaks compared with those considering wave passage only. The above observations demonstrate that uniform ground motion will lead to the unrealistic prediction of the bridge responses. Non-uniform seismic excitations considering only the time delay could still underestimate the relative displacement responses between adjacent segments and the therefore the pounding and unseating potentials, even though the adjacent bridge structures have the same dynamic properties. The results also reveal that matching the fundamental periods of the adjacent bridge frames close to each other as suggested in current bridge design codes is not sufficient to mitigate pounding response and opening relative displacement when spatially varying ground motions are considered.

Figure 17(b) compares the joint relative displacement responses with highly (Case RL3), intermediately (RL4), weakly correlated (RL5) excitations based on the Class III site condition. The figure shows that highly and weakly correlated ground motions caused a larger 
relative displacement than the ground motions with intermediately correlation. The response caused by highly correlated ground motions is slightly lower than that induced by weakly correlated ground motions. Comparing the results of Case RL3-RL5 in Table 6 shows that weakly and highly correlated ground motions cause the largest and smallest acceleration peaks, respectively.

Joint relative displacement responses of the bridge due to different soil site conditions are shown in Figure 17(c). Spatially varying ground motions on site Class IV (Case RL7) caused the largest out-of-phase movements between two adjacent frames and the largest acceleration peaks. The ground motions corresponding Class I site condition resulted in very small relative displacement responses. It is apparent from the presented results that bridge founded on softer soil condition are subjected to larger asynchronous vibration between adjacent structure components and hence the more risks of pounding and unseating.

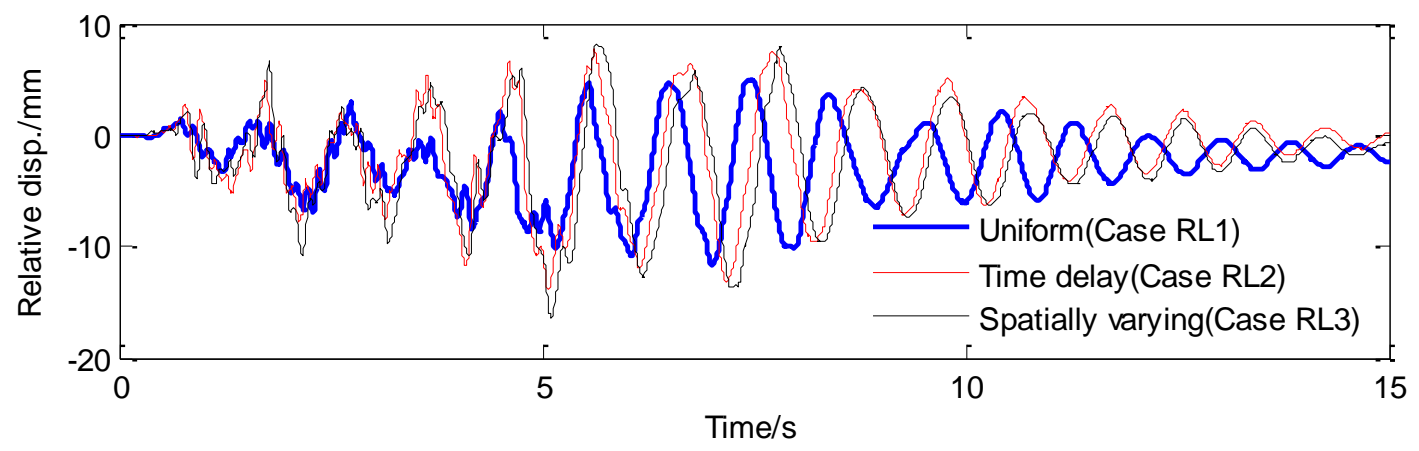

(a)

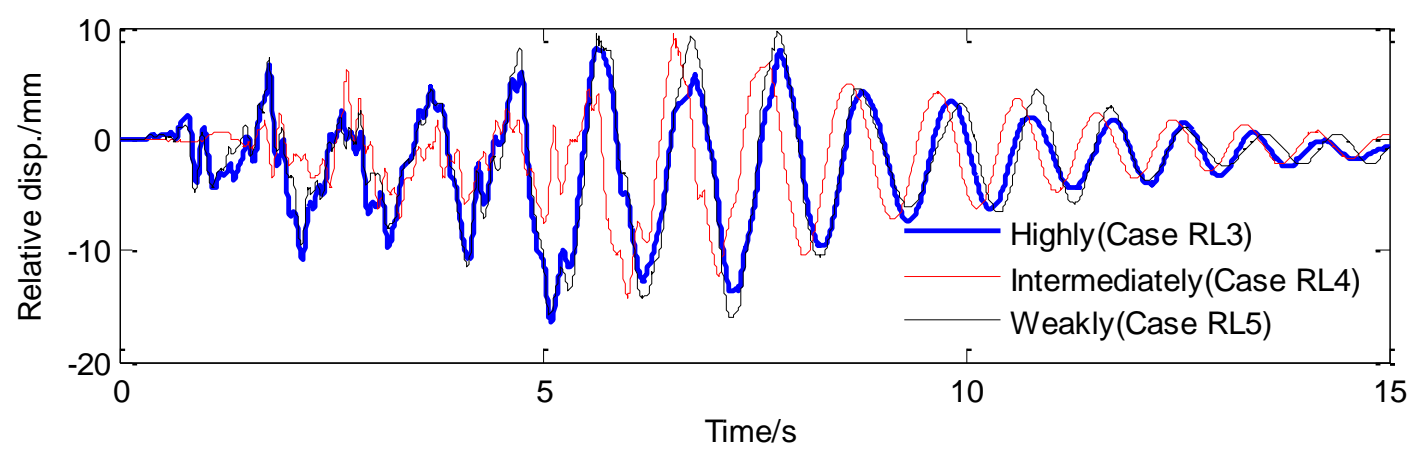

(b) 


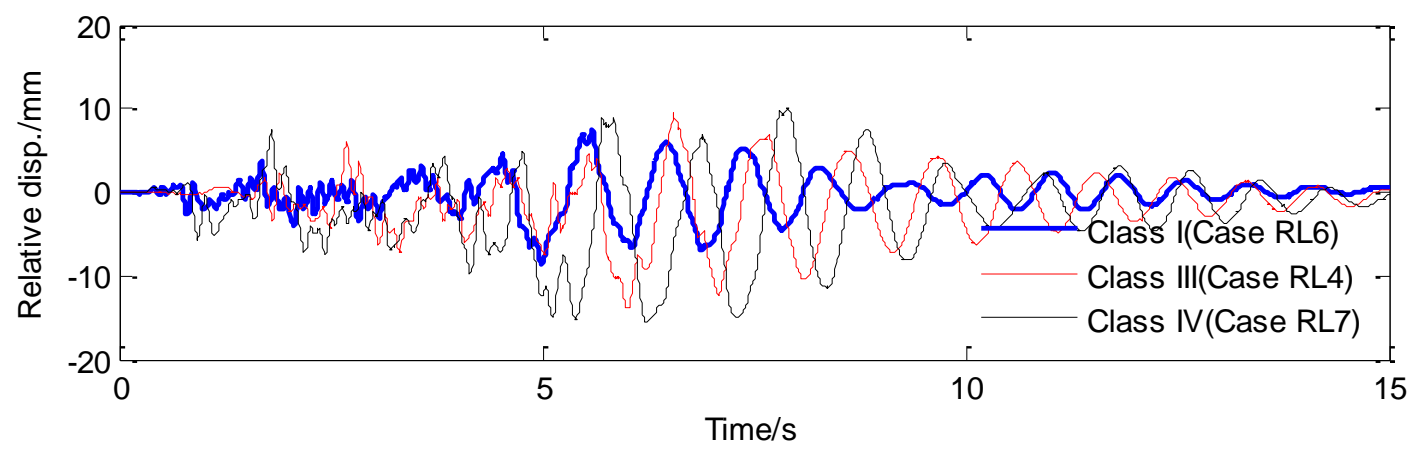

(c)

Fig.17 Relative displacement at the North side of the joint, (a) considering different seismic excitation, (b) considering different coherency loss, (c) considering different site conditions

Table 6 Detected pounding in low intensity cases

\begin{tabular}{cccccc}
\hline $\begin{array}{c}\text { Case } \\
\text { No. }\end{array}$ & $\begin{array}{c}\text { Number of } \\
\text { pounding }\end{array}$ & $\begin{array}{c}\text { Acceleration } \\
\text { peak }\left(\mathrm{m} / \mathrm{s}^{2}\right)\end{array}$ & $\begin{array}{c}\text { Case } \\
\text { No. }\end{array}$ & $\begin{array}{c}\text { Number of } \\
\text { pounding }\end{array}$ & $\begin{array}{c}\text { Acceleration } \\
\text { peak }\left(\mathrm{m} / \mathrm{s}^{2}\right)\end{array}$ \\
\hline RL1 & No & 3.23 & FL1 & No & 3.40 \\
RL2 & 2 & 4.67 & FL2 & No & 2.64 \\
RL3 & 1 & 5.14 & FL3 & No & 2.59 \\
RL4 & 1 & 5.44 & FL4 & No & 2.52 \\
RL5 & 1 & 6.10 & FL5 & No & 3.00 \\
RL6 & No & 2.57 & FL6 & No & 2.16 \\
RL7 & 2 & 9.35 & FL7 & No & 3.04 \\
\hline
\end{tabular}

\subsection{Effect of foundation rocking}

Many researches propose using rocking foundation to mitigate the seismic response of bridge structures, and extensive experimental and numerical investigations were carried out. Most of the existing experimental studies are limited to a single bridge pier. In order to study the effect of foundation type on the structure response and pounding response, the responses of the bridge models with rocking foundations are compared with those with fixed foundations in this section.

Figure 18 presents the time histories of curvature responses in the longitudinal direction of Pier 2 at the top and base of the pier for Cases FL5 and RL5. It is apparent that the pier experienced the larger curvature responses at both top and bottom in Case FL5 than in Case 
RL5. For better understanding such effect, the comparisons between the curvature peaks of bridge piers with two foundation types for all $0.25 \mathrm{~g}$ cases are shown in Figure 19. It is obvious that the curvature responses are always smaller for the piers with the rocking foundation than on the fixed foundation when subjected to the same ground motions. These observations demonstrate the effectiveness of using rocking foundations in reducing the seismic bending responses of bridge piers.

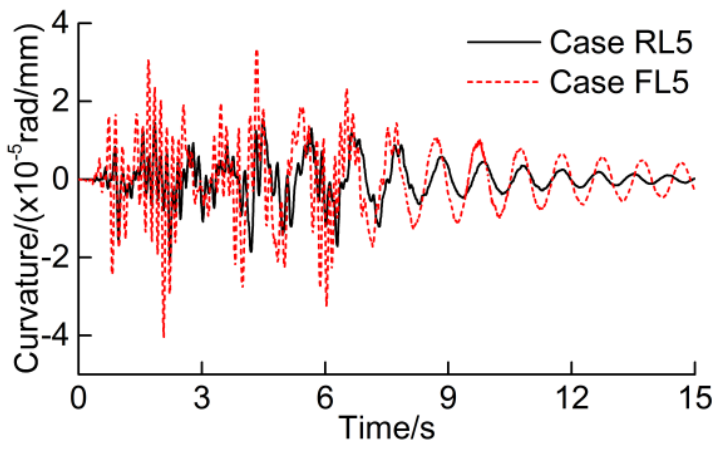

(a)

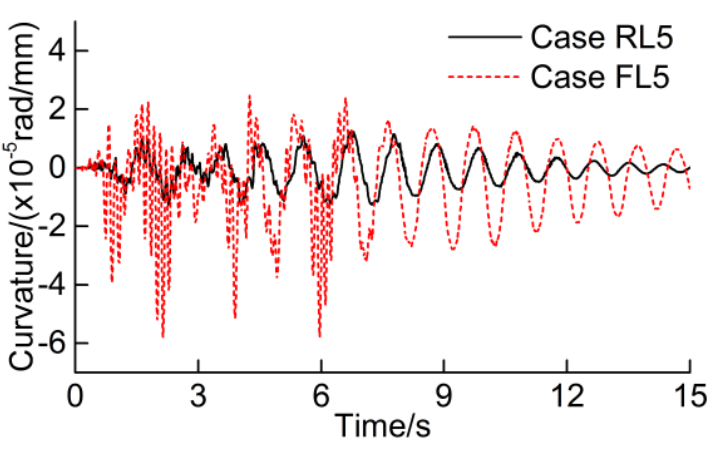

(b)

Fig.18 Time history of the curvature at (a) the top of pier, (b) at the bottom of pier

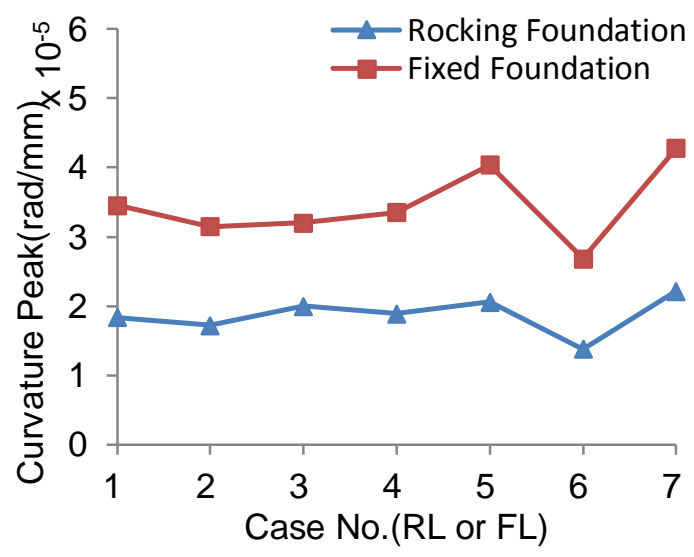

(a)

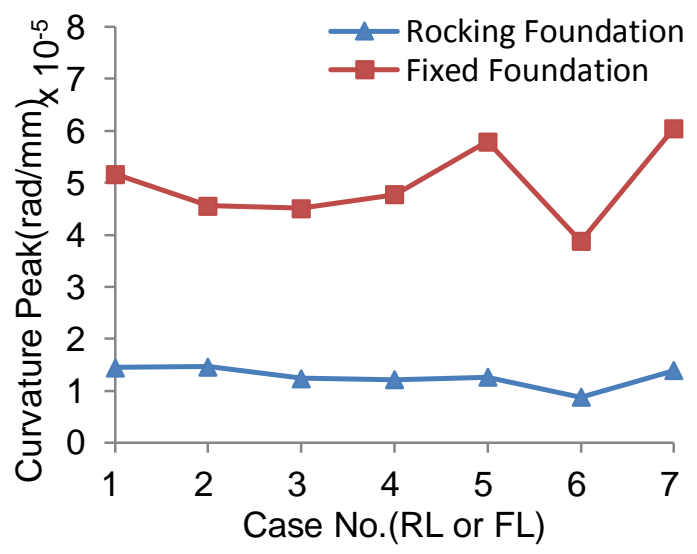

(b)

Fig.19 Comparison of the pier curvature peaks (a) at the top (b) at the bottom

During the rocking foundation cases the uplifting of foundations is observed. Taking Case RL5 for example, the uplifting displacement responses at north-west (shown in Figure 4) and 
north-east corners of the foundation of Frame 2 are shown in Figure 20, where the positive values represent the uplifting. The results indicate that rocking foundation caused a significant uplifting at all corners of bases and the uplifting reaches as large as $3.099 \mathrm{~mm}$ at the north-west corner. This uplifting response is large enough to cause a significant rigid rotation of whole models. The time histories shown in Figure 21 depict the longitudinal absolute displacements at the top of piers in Cases RL5 and FL5. It can be observed that rocking foundation increases the absolute displacement responses at the top of piers compared to the fixed foundation.

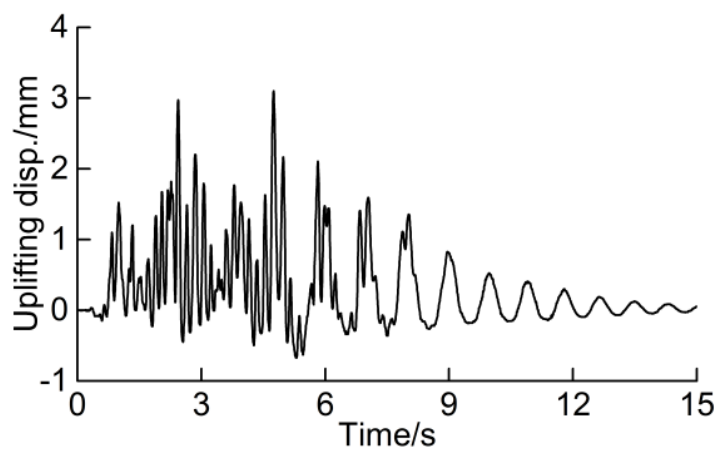

(a)

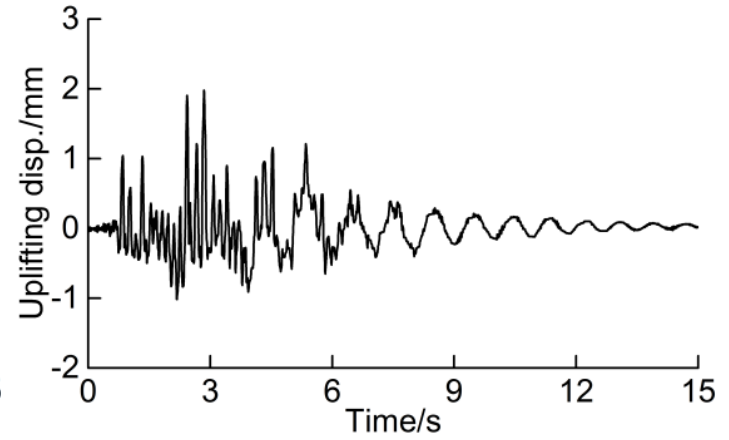

(b)

Fig.20 Foundation uplifting of Frame 2, (a) north-west corner, (b) north-east corner

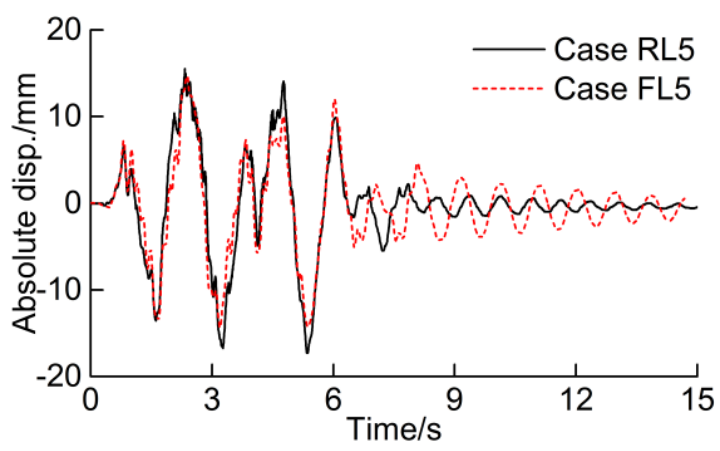

(a)

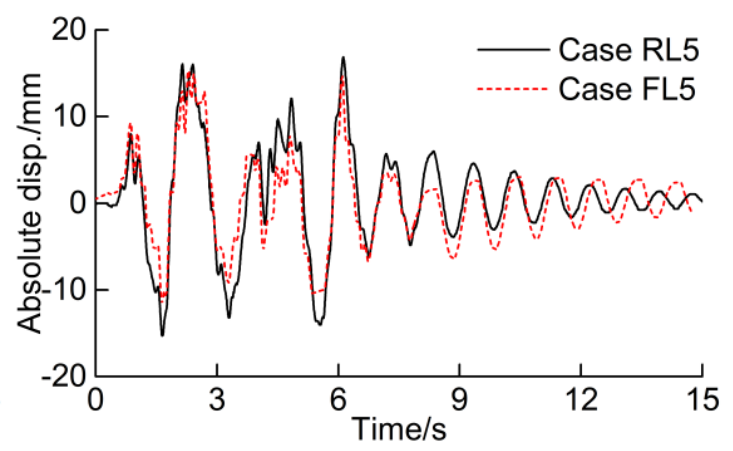

(b)

Fig.21 Longitudinal absolute displacements at the top of piers, (a) Pier1, (b) Pier2

Figure 22(a) presents the relative displacement responses of Cases RL5 and FL5. As shown, during the duration of 0-9 s, the relative displacements at the north side in Case RL5 are 
obviously larger than those in Case FL5, in both closing and opening directions. The in Case RL5 reaches $8.652 \mathrm{~mm}$ at $5.58 \mathrm{~s}$, which is larger than the initial gap of $8 \mathrm{~mm}$ between two decks, which means two decks come into contact with each other. It should be noted that this closing relative displacement is $0.652 \mathrm{~mm}$ higher than the gap width, this is actually due to the vertical free vibration of the deck that affected the relative displacement measurement. The maximum value of closing relative displacements in Case FL5 is only $6.78 \mathrm{~mm}$ at $5.63 \mathrm{~s}$, which is less than the initial gap. It means no pounding occurs in Case FL5. The opening relative displacements reach $14.27 \mathrm{~mm}$ and $7.645 \mathrm{~mm}$ in Case RL5 and FL5, respectively. The same phenomenon is also observed for the south side.

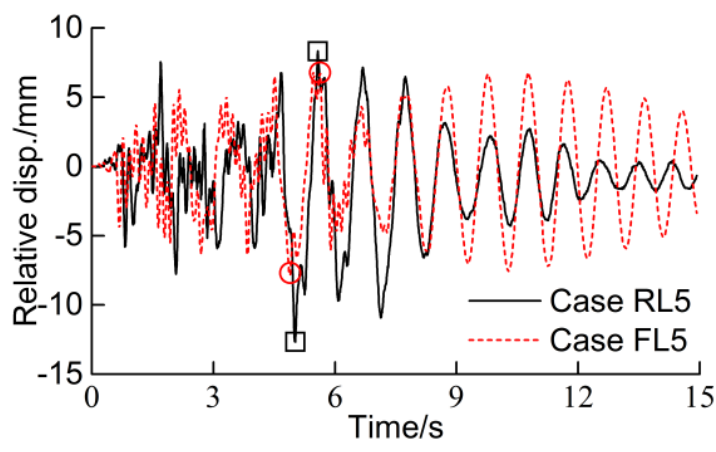

(a)

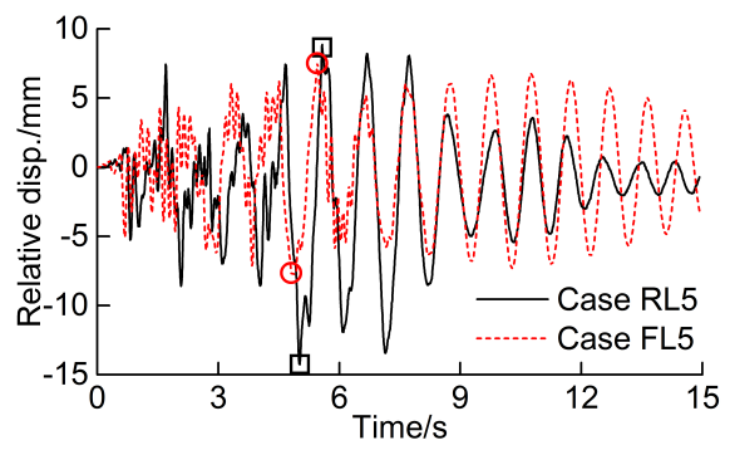

(b)

Fig.22 Relative displacements between the decks, (a) North side, (b) South side

Figure 23 summarizes and compares the peaks of opening relative displacements between two decks at both north and south sides. It is obvious that the opening relative displacement responses on the rocking foundation are always larger than those on the fixed foundation when subjected to the same ground motions. It can be seen from Table 6 that pounding happen in most cases with rocking foundation, except for Case RL1 and RL6. No pounding is observed in fixed foundation cases. The above observation demonstrates that rocking foundation is effective in mitigating the seismic effect on pier responses. However, rocking 
foundation results in larger displacement response of bridge superstructures and hence increases pounding between adjacent decks and unseating potentials.

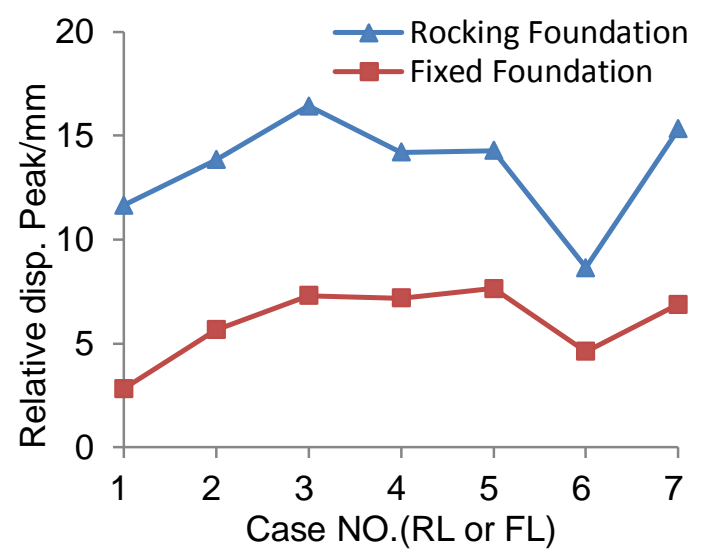

(a)

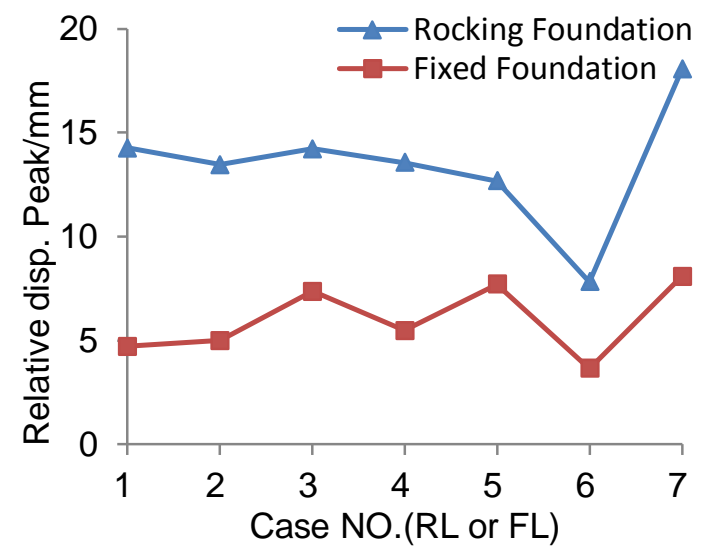

(b)

Fig. 23 Comparison of relative displacements peaks, (a) North side, (b) South side

\subsection{Simulation of experimental results}

Case FH4 is simulated in LS_DYNA by using the numerical model developed in Section 4. The numerical results including acceleration response at joint corners and deck damages are compared with the experimental results. The time-history of pounding force is also obtained . Figure 24 shows the longitudinal accelerations at the corner of the joint . It can be seen that the numerical result agrees well with the experimental data. Three poundings occur during the simulation, at $1.649 \mathrm{~s}, 4.102 \mathrm{~s}$, and $5.987 \mathrm{~s}$, respectively. The numerical model reasonably captures the instances of pounding. However, the acceleration impulse amplitudes predicted by FE model are slightly smaller than the experiment results. 


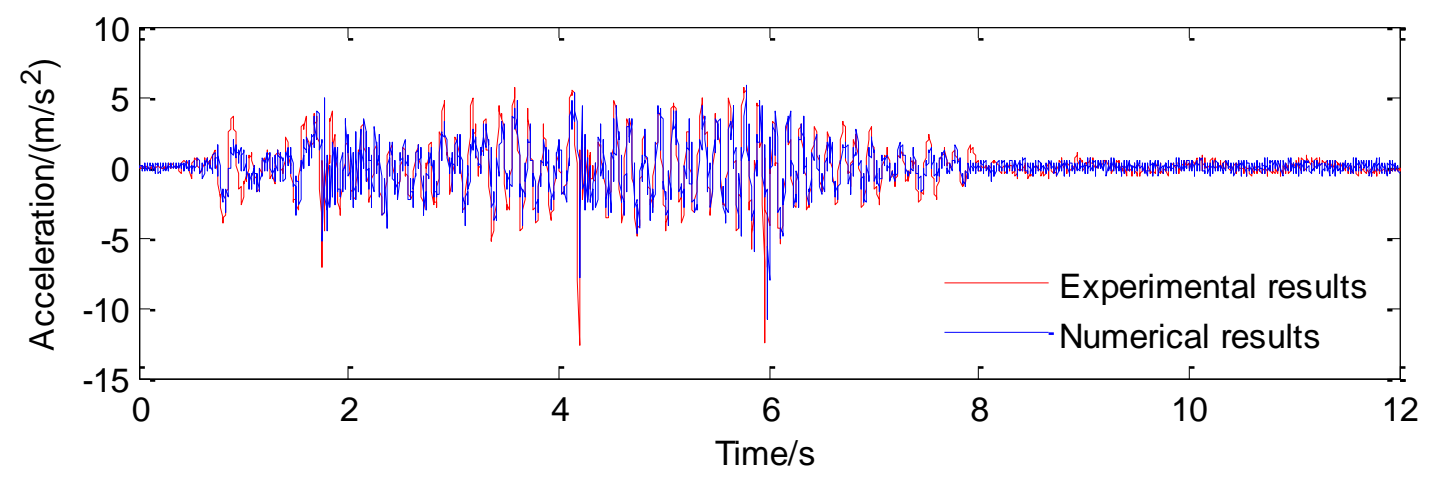

Fig.24 Comparison of the numerical and experimental acceleration at the joint in the longitudinal direction

Figure 25 compares the numerical and experimental damage patterns after Case FH4. It can be seen that three poundings occur between the bridge girders at the southern side. Large pounding force (Figure 26) results in the spalling of the concrete at the localized area. It can be seen that the numerical damage pattern matches well with the observed local concrete damages in the experiments. However, it is noted that area of concrete spalling predicted by the numerical model is slightly smaller than that observed during the test.

Figure 26 presents the time history of pounding forces between two adjacent decks. The time history indicates that the pounding forces are $140.9 \mathrm{kN}, 216.5 \mathrm{kN}$, and $208.5 \mathrm{kN}$ at $1.649 \mathrm{~s}$, 4.102s, and $5.987 \mathrm{~s}$, respectively. The second pounding resulted in the largest pounding force. Such large impact forces are likely to cause acceleration impulses and localized damage to the neighboring bridge decks as observed above.

Numerical results show that the developed numerical model can be used to accurately predict the pounding responses, pounding locations and pounding damage caused by seismic motions with reasonable accuracy. 


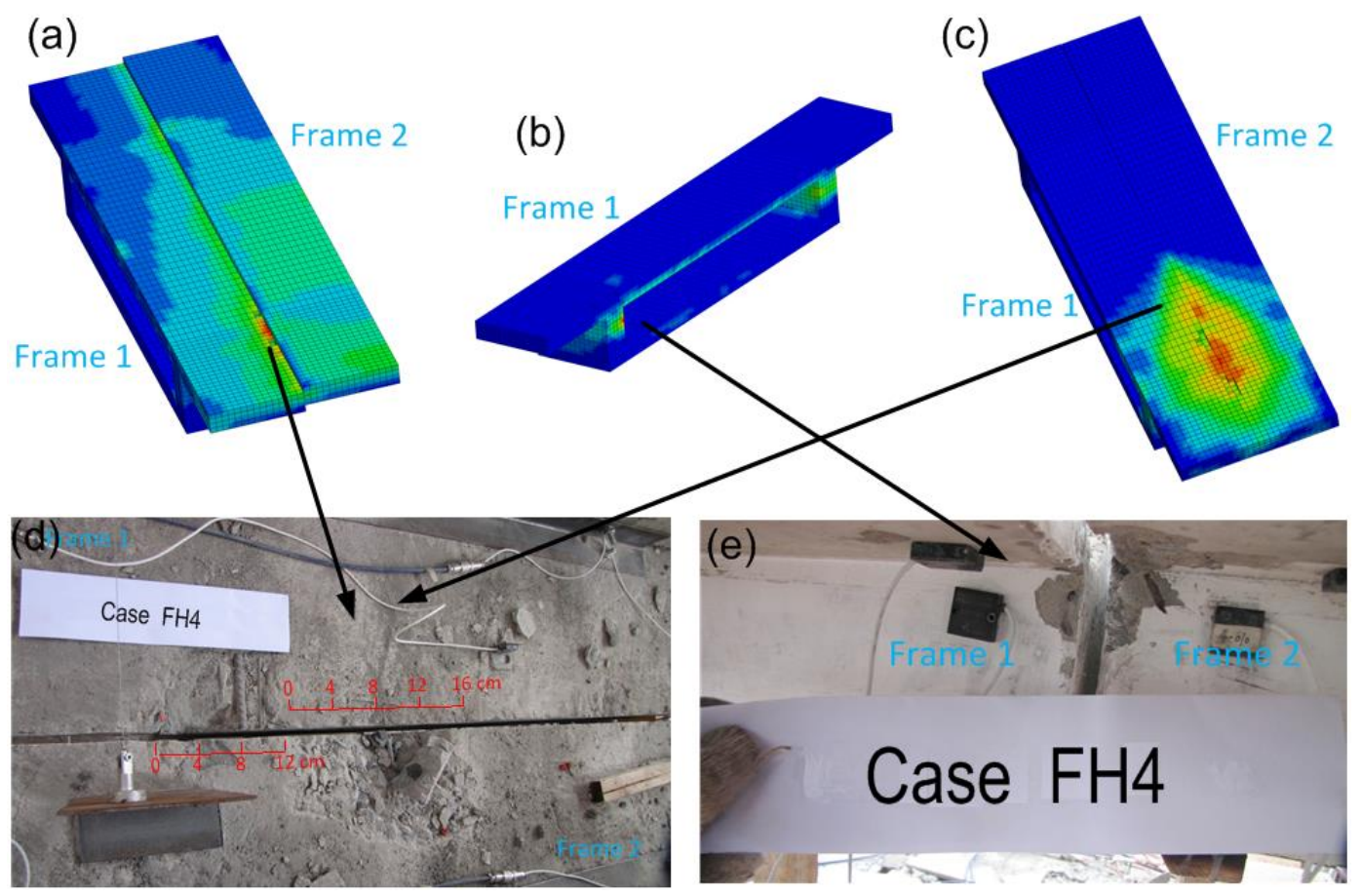

Fig.25 damage patterns obtained from the numerical ( $a, b$ and $c)$ and experimental ( $d$ and e) results after case FH4 (a) $t=1.649 \mathrm{~s}$, (b) $\mathrm{t}=4.102 \mathrm{~s}$, (c) $\mathrm{t}=5.987 \mathrm{~s}$

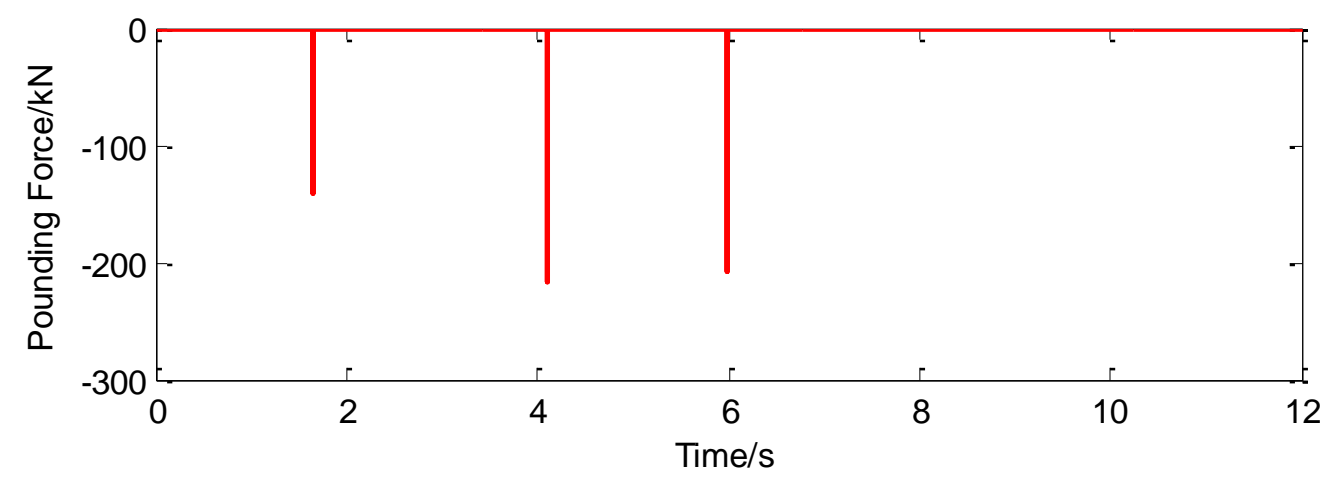

Fig.26 Pounding force time history

\section{Conclusions}

In the present paper, the pounding phenomenon between adjacent bridge decks is investigated via experimental testing and numerical simulation. Bridge test models including two bridge frames were designed and constructed based on the similarity law, and various experimental studies were carried out by using a shaking table array system located in Central South University, China. The bridge models were subjected to stochastically simulated ground 
motions in bi-directions based on the response spectra of the Chinese Guideline for Seismic Design of Highway Bridge for three different soil site conditions (Class I, Class III site and Class IV), and three coherency loss levels. The influences of pounding, spatially varying ground motions and boundary conditions on the bridge responses are investigated. Moreover, a detailed 3D finite element model is developed to simulate one of the experimental cases. Following conclusions are drawn based on the experimental and numerical results:

- Pounding can increase the acceleration responses of bridge decks. Wavelet transform method can be used to accurately detect the pounding instants. Pounding can cause severe localized damages to the bridge decks.

- The stiff frame is more sensitive to deck acceleration responses resulting from pounding than the flexible frame. For the case presented in this study, poundings of adjacent segments result in a reduction of the responses of the piers.

- Spatially varying ground motions have a significant influence on the structural responses. Spatially varying ground motions can increase the relative displacement responses and therefore the pounding and unseating potentials. Both local site conditions and coherency loss can obviously affect the relative displacements and pounding responses. Softer site results in the larger opening relative displacement and higher pounding responses.

- Rocking foundation greatly increases the relative displacement responses between bridge decks and exacerbates the pounding and unseating potentials of the bridge superstructures, while it can decrease the bending moment developed in the bridge piers.

- Numerical simulation agrees well with the experimental results, the developed numerical model can be adopted to accurately predict the seismic responses and pounding induced damages to bridge structures. 


\section{Acknowledgments}

Financial support from the National Natural Science Foundation of China under Grant No. 51278163 is acknowledged. The partial financial support from ARC Linkage project LP110200906 for carrying out this research is also appreciated.

\section{References}

Anagnostopoulos, S. A. (1988). "Pounding of buildings in series during earthquakes", Earthquake engineering \& structural dynamics, Vol.16, No.3, pp. 443-456.

Anagnostopoulos, S. A. (2004). "Equivalent viscous damping for modeling inelastic impacts in earthquake pounding problems", Earthquake engineering \& structural dynamics, Vol.33, No.8, pp. 897-902.

Anagnostopoulos, S. A. and Spiliopoulos, K. V. (1992). “An investigation of earthquake induced pounding between adjacent buildings", Earthquake engineering \& structural dynamics, Vol.21, No.4, pp. 289-302.

Bi, K. M. and Hao, H. (2012). "Modelling and simulation of spatially varying earthquake ground motions at sites with varying conditions", Probabilistic engineering mechanics, Vol.29, pp. 92-104.

Bi, K. M. and Hao, H. (2013). "Numerical simulation of pounding damage to bridge structures under spatially varying ground motions", Engineering Structures, Vol.46, pp. $62-76$

Bi, K. M. and Hao, H. (2015). "Modelling of shear keys in bridge structures under seismic loads", Soil Dynamics and Earthqhuake Engineering, Vol. 74, pp. 56-68.

Bi, K. M., Hao, H. and Chouw, N. (2010). "Required separation distance between decks and at abutments of a bridge crossing a canyon site to avoid seismic pounding”, Earthquake 
Engineering \& Structural Dynamics, Vol.39, No.3, pp. 303-323.

Bi, K. M., Hao, H. and Chouw, N. (2011). "Influence of ground motion spatial variation, site condition and SSI on the required separation distances of bridge structures to avoid seismic pounding”, Earthquake Engineering \& Structural Dynamics, Vol.40, No.9, pp. 1027-1043.

Bi, K. M., Hao, H. Chouw, N. (2013). “3D FEM analysis of pounding response of bridge structures at a canyon site to spatially varying ground motions", Advances in Structural Engineering, Vol. 16, No. 4, pp. 619-640.

Caltrans (2010). Seismic Design Criteria: Design Manual-Version 1.6, California Dept. of Transportation, Sacramento, CA, USA.

Chau, K. T. and Wei, X. X. (2001). "Pounding of structures modelled as non-linear impacts of two oscillators", Earthquake engineering \& structural dynamics, Vol.30, No.5, pp. 633-651.

Chau, K. T., Wei, X. X., Guo, X. and Shen, C. Y. (2003). "Experimental and theoretical simulations of seismic poundings between two adjacent structures", Earthquake engineering \& structural dynamics, Vol.32, No.4, pp. 537-554.

Chouw, N. and Hao, H. (2008a). "Significance of SSI and non-uniform near-fault ground motions in bridge response II: Effect on response with modular expansion joint", Engineering Structures, Vol.30, No.1, pp. 154-162.

Chouw, N. and Hao, H. (2008b). "Significance of SSI and nonuniform near-fault ground motions in bridge response I: Effect on response with conventional expansion joint", Engineering Structures, Vol.30, No.1, pp. 141-153.

Chouw, N. and Hao, H. (2012). "Pounding Damage to Buildings and Bridges in the 22 February 2011 Christchurch Earthquake”, International Journal of Protective Structures, Vol.3, No.2, pp. 123-140. 
Cole, G., Dhakal, R., Carr, A. and Bull, D. (2011). "An investigation of the effects of mass distribution on pounding structures", Earthquake Engineering \& Structural Dynamics, Vol.40, No.6, pp. 641-659.

Comité Euro-International du Béton (1993). CEB-FIP Model Code 1990, Redwood Books. Trowbridge, Wiltshire, UK.

Davis, R. (1992). "Pounding of buildings modelled by an impact oscillator", Earthquake engineering \& structural dynamics, Vol.21, No.3, pp. 253-274.

Deodatis, G. (1996). "Non-stationary stochastic vector processes: seismic ground motion applications", Probabilistic Engineering Mechanics, Vol.11, No.3, pp. 149-167.

Filiatrault, A., Wagner, P. and Cherry, S. (1995). "Analytical prediction of experimental building pounding", Earthquake engineering \& structural dynamics, Vol.24, No.8, pp. $1131-1154$

Guo, A. X., Li, Z. J. and Li, H. (2011). "Point-to-surface pounding of highway bridges with deck rotation subjected to bi-directional earthquake excitations", Journal of Earthquake Engineering, Vol.15, No.2, pp. 274-302.

Guo, A. X., Li, Z. J., Li, H. and Ou, J. P. (2009). "Experimental and analytical study on pounding reduction of base-isolated highway bridges using MR dampers", Earthquake Engineering \& Structural Dynamics, Vol.38, No.11, pp. 1307-1333.

Hao, H. (1998). “A parametric study of the required seating length for bridge decks during earthquake”, Earthquake Engineering \& Structural Dynamics, Vol.27, No.1, pp.91-103.

Hao, H., Bi, K. M., Chouw, N. and Ren, W. X. (2013). "State-of-the-art review on seismic induced pounding response of bridge structures", Journal of Earthquake and Tsunami, Vol.7, No.3.

Hao, H. and Liu, X. Y. (1998). "Estimation of required separations between adjacent 
structures under spatial ground motions", Earthquake Engineering, Vol.2, No.2, pp. 197-215.

Hao, H., Oliveira, C. and Penzien, J. (1989). "Multiple-station ground motion processing and simulation based on SMART-1 array data", Nuclear Engineering and Design, Vol.111, No.3, pp. 293-310.

Hao, H. and Shen, J. (2001). "Estimation of relative displacement of two adjacent asymmetric structures”, Earthquake Engineering \& Structural Dynamics, Vol.30, No.1, pp. 81-96.

Hao, H. and Zhang, S. R. (1999). "Spatial ground motion effect on relative displacement of adjacent building structures", Earthquake Engineering \& Structural Dynamics, Vol.28, No.4, pp. 333-349.

Jankowski, R. (2005). "Non-linear viscoelastic modelling of earthquake-induced structural pounding”, Earthquake engineering \& structural dynamics, Vol.34, No.6, pp. 595-611.

Jankowski, R. (2006). "Analytical expression between the impact damping ratio and the coefficient of restitution in the non-linear viscoelastic model of structural pounding", Earthquake engineering \& structural dynamics, Vol.35, No.4, pp. 517-524.

Jankowski, R. (2007). “Theoretical and experimental assessment of parameters for the non-linear viscoelastic model of structural pounding", Journal of Theoretical and Applied Mechanics, Vol.45, pp. 931-942.

Jankowski, R. (2009). 'Non-linear FEM analysis of earthquake-induced pounding between the main building and the stairway tower of the Olive View Hospital", Engineering Structures, Vol. 31, No. 8, pp. 1851-1864.Jankowski, R. (2010). "Experimental study on earthquake-induced pounding between structural elements made of different building materials", Earthquake Engineering \& Structural Dynamics, Vol.39, No.3, pp. 343-354.

Jankowski, R., Wilde, K. and Fujino, Y. (1998). "Pounding of superstructure segments in 
isolated elevated bridge during earthquakes", Earthquake engineering \& structural dynamics, Vol.27, No.5, pp. 487-502.

Jeng, V. and Kasai, K. (1996). "Spectral relative motion of two structures due to seismic travel waves", Journal of Structural Engineering, Vol.122, No.10, pp. 1128-1135.

Johnson, N. S., Saiidi, M. and Sanders, D. H. (2006). Large-Scale Experimental and Analytical Seismic Studies of A Two-Span Reinforce Concrete Bridge System, University of Nevada, Reno, Nevada, USA.

JTG/T B02-01-2008 (2008). Guideline for Seismic Design of Highway Bridge, China Communications Press, Beijing,China. (In Chinese)

Kawashima, K. and Unjoh, S. (1997). "The damage of highway bridges in the 1995 hyogo-ken nanbu earthquake and its impact on japanese seismic design", Journal of Earthquake Engineering, Vol.1, No.3, pp. 505-541.

Kawashima, K., Unjoh, S., Hoshikuma, J. I. and Kosa, K. (2011). "Damage of Bridges due to the 2010 Maule, Chile, Earthquake", Journal of Earthquake Engineering, Vol.15, No.7, pp. 1036-1068.

Khatiwada, S. and Chouw, N. (2014). "Limitations in Simulation of Building Pounding in Earthquakes", International Journal of Protective Structures, Vol.5, No.2, pp. 123-150.

Khatiwada, S., Chouw, N. and Butterworth, J. W. (2014). "A generic structural pounding model using numerically exact displacement proportional damping", Engineering Structures, Vol.62-63, pp. 33-41.

Kim, S. H. and Shinozuka, M. (2003). "Effects of seismically induced pounding at expansion joints of concrete bridges", Journal of engineering mechanics, Vol.129, No.11, pp. $1225-1234$.

Komodromos, P., Polycarpou, P. C., Papaloizou, L. and Phocas, M. C. (2007). "Response of 
seismically isolated buildings considering poundings", Earthquake Engineering \& Structural Dynamics, Vol.36, No.12, pp. 1605-1622.

Li, B., Bi, K. M., Chouw, N., Butterworth, J. W. and Hao, H. (2012). "Experimental investigation of spatially varying effect of ground motions on bridge pounding", Earthquake Engineering \& Structural Dynamics, Vol.41, No.14, pp. 1959-1976.

Li, J. Z., Peng, T. B. and Xu, Y. (2008). "Damage investigation of girder bridges under the Wenchuan earthquake and corresponding seismic design recommendations", Earthquake Engineering and Engineering Vibration, Vol.7, No.4, pp. 337-344.

Maison, B. F. and Kasai, K. (1992). "Dynamics of pounding when two buildings collide", Earthquake engineering \& structural dynamics, Vol.21, No.9, pp. 771-786.

Malhotra, P. (1998). "Dynamics of seismic pounding at expansion joints of concrete bridges", Journal of Engineering Mechanics, Vol.124, No.7, pp. 794-802.

Malhotra, P. K., Huang, M. J. and Shakal, A. F. (1995). "Seismic interaction at separation joints of an instrumented concrete bridge", Earthquake Engineering \& Structural Dynamics, Vol.24, No.8, pp. 1055-1067.

Malvar, L. J. (1998). "Review of static and dynamic properties of steel reinforcing bars", ACI Materials Journal, Vol.95, No.5.

Moehle, J. P. and Eberhard, M. O. (2000). Earthquake Damage to Bridges, Bridge Engineering Handbook. Chouw, N. and Hao, W. F. and Duan, L., CRC Press: Boca Raton.

Mondal, G. and Rai, D. C. (2008). "Performance of harbour structures in Andaman Islands during 2004 Sumatra earthquake”, Engineering Structures, Vol.30, No.1, pp. 174-182.

Mouzakis, H. P. and Papadrakakis, M. (2004). "Three dimensional nonlinear building pounding with friction during earthquakes", Journal of Earthquake Engineering, Vol.08, No.1, pp. 107-132. 
Muthukumar, S. and DesRoches, R. (2006). "A Hertz contact model with non-linear damping for pounding simulation", Earthquake engineering \& structural dynamics, Vol.35, No.7, pp. 811-828.

Pantelides, C. and Ma, X. (1998). "Linear and non-linear pounding of structural systems", Computers \& Structures, Vol.66, No.1, pp. 79-92.

Papadrakakis, M. and Mouzakis, H. P. (1995). "Earthquake simulator testing of pounding between adjacent buildings", Earthquake engineering \& structural dynamics, Vol.24, No.6, pp. 811-834.

Penzien, J. (1997). "Evaluation of building separation distance required to prevent pounding during strong earthquakes", Earthquake Engineering \& Structural Dynamics, Vol.26, No.8, pp. 849-858.

Ren, W. X., Xu, X. X. and Yan, W. J. (2013). “Operational modal parameter identification based on covariance-driven continuous wavelet transform and singular value decomposition", Advances in Structural Engineering, Vol.16, No.3, pp. 579-592.

Ruangrassamee, A. and Kawashima, K. (2001). "Relative displacement response spectra with pounding effect", Earthquake Engineering \& Structural Dynamics, Vol.30, No.10, pp. $1511-1538$.

Shrestha, B., Hao, H. and Bi, K. M. (2014). "Effectiveness of using rubber bumper and restrainer on mitigating pounding and unseating damage of bridge structures subjected to spatially varying ground motions”, Engineering Structures, Vol.79, pp. 195-210.

Shrestha, B., Hao, H. and Bi, K. (2015) "Seismic Response Analysis of Multiple-Frame Bridges with Unseating Restrainers Considering Ground Motion Spatial Variation and SSI", Advances in Structural Engineering, Vol.18, No.6, pp. 873-892.

Sobzcky, K. (1991). Stochastic Wave Propagation. Kluwer Academic Publishers, Netherlands. 
Tanabe, T., Machida, A., Higai, T. and Matsumoto, N. (1998). "General view of the reasons for seismic damages for bridge piers and columns of elevated bridges at Hyogoken-Nanbu earthquake", Proceedings of Structural Engineering World Congress, ASCE, San Francisco, USA, July.

Tang, E. K. and Hao, H. (2010). "Numerical simulation of a cable-stayed bridge response to blast loads, Part I: Model development and response calculations”, Engineering Structures, Vol.32, No.10, pp. 3180-3192.

Uenishi, K., Sakurai, S., Uzarski, S. M. J. and Arnold, C. (1999). "Chi-Chi Taiwan, earthquake of September 21, 1999: reconnaissance report", Earthquake Spectra, Vol.5, No.19, pp. 153-173.

Van Mier, J. G. M., Pruijssers, A. F., Reinhardt, H. W. and Monnier, T. (1991). "Load-time response of colliding concrete bodies", Journal of Structural Engineering, Vol.117, No.2, pp. 354-374.

Wieser, J., Maragakis, E., Buckle, I. and Zaghi, A. (2012). "Experimental evaluation of seismic pounding at seat-type abutments of horizontally curved bridges". Proceedings of 15th World Conference on Earthquake Engineering, Barani, S., Massa, M., Lovati, S., et al., Lisbon, Portugal, September.

Xing, S. T., Halling, M. W. and Meng, Q. L. (2012). “Structural Pounding Detection by Using Wavelet Scalogram", Advances in Acoustics and Vibration, Vol.2012.

Ye, K., Li, L. and Zhu, H. P. (2009). "A note on the Hertz contact model with nonlinear damping for pounding simulation", Earthquake Engineering \& Structural Dynamics, Vol.38, No.9, pp. 1135-1142.

Zhu, P., Abe, M. and Fujino, Y. (2002). "Modelling three-dimensional non-linear seismic performance of elevated bridges with emphasis on pounding of girders", Earthquake 
engineering \& structural dynamics, Vol.31, No.11, pp. 1891-1913. 